
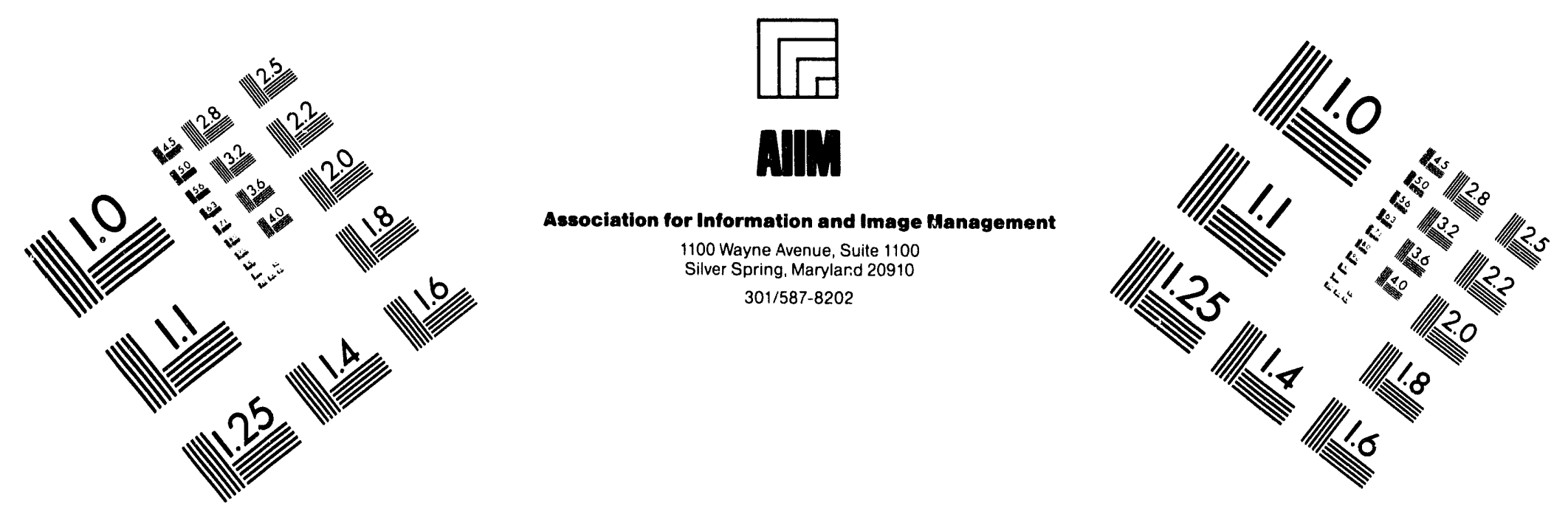

\title{
Centimeter
}

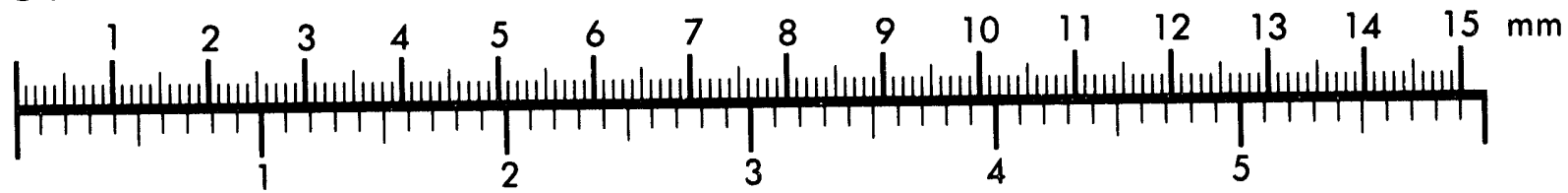
Inches
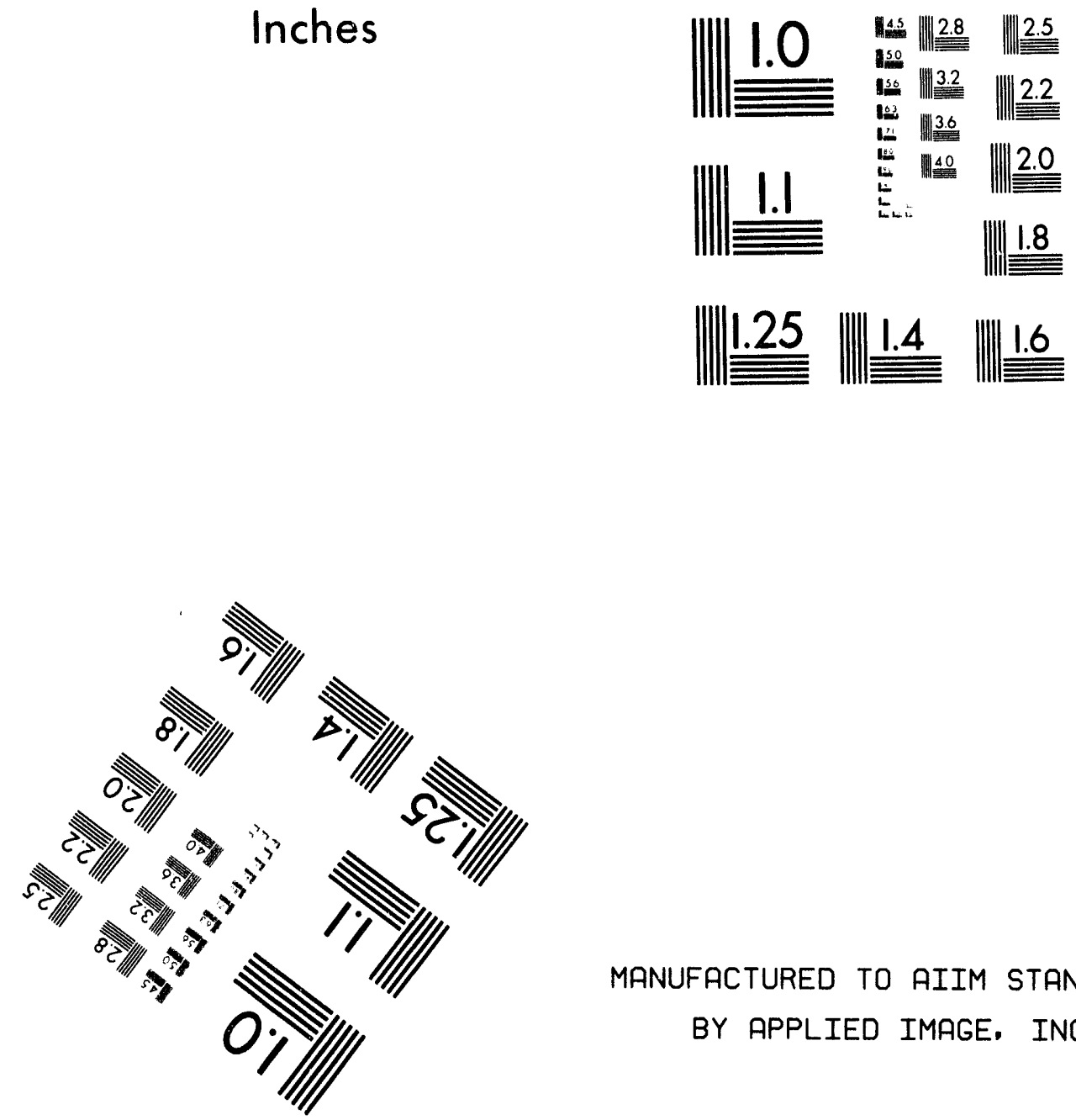

MANUFACTURED TO AIIM STANDARDS

BY APPLIED IMAGE, INC.

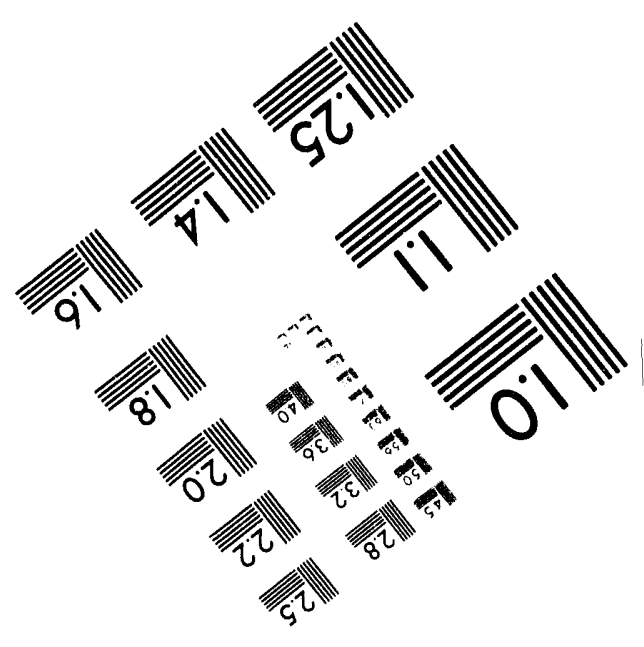



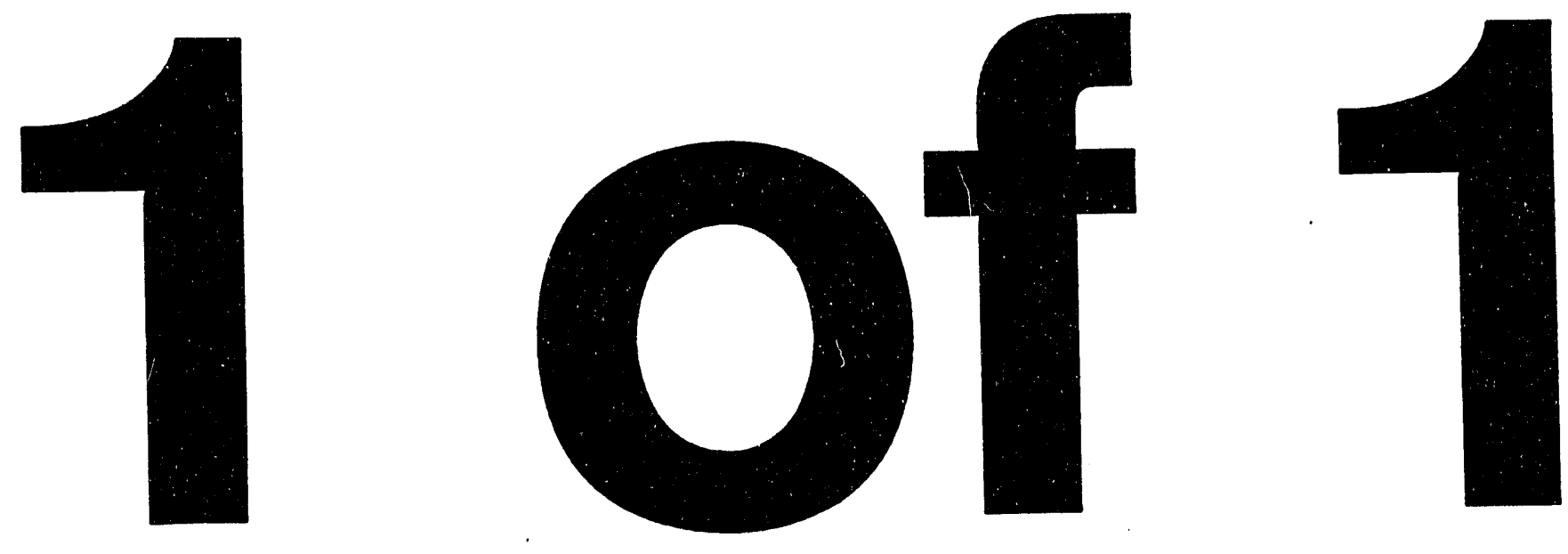


\section{Advanced Energy Projects FY 1994 Research Summaries}

\section{September 1994}

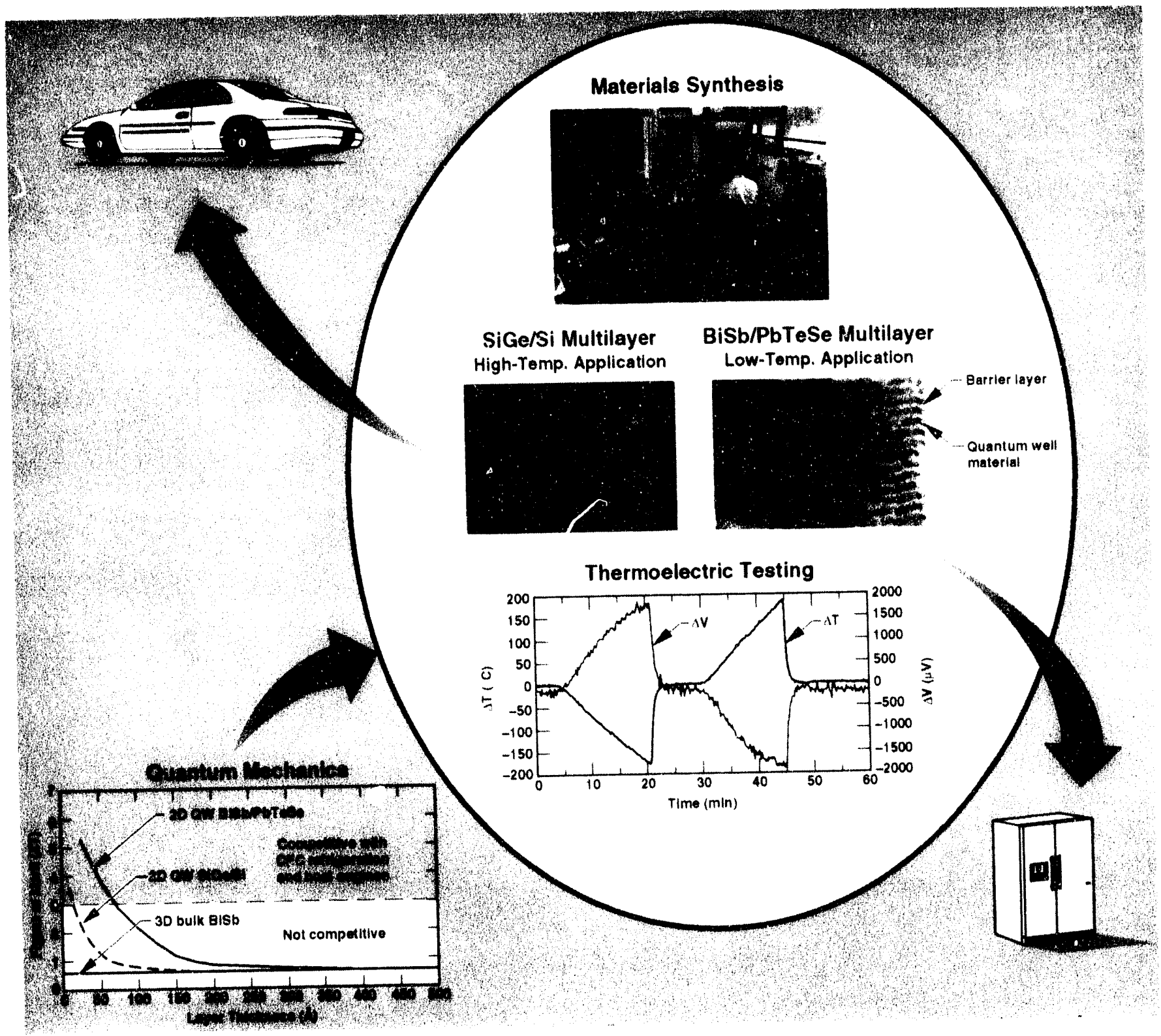

\section{US Department of Energy}

Office of Energy Research

Office of Basic Energy Sciences

Division of Advanced Energy Projects

Washington, D.C. 20585

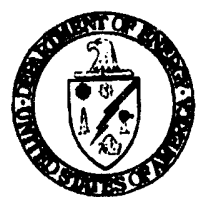




\section{TABLE OF CONTENTS}

PROGRAM OVERVIEW $\ldots \ldots \ldots \ldots \ldots \ldots \ldots \ldots \ldots$

SUMMARIES OF PROJECTS ACTIVE IN FY $1994 \ldots \ldots \ldots \ldots$

GRANT AND LABORATORY PROGRAMS . . . . . . . . . . . . . . 7

SMALL BUSINESS ININOVATION RESEARCH PROGRAM . . . . . . 61

\section{APPENDICES}

A. SAMPLE STATEMENT OF WORK . . . . . . . . . . . . 83

B. PROGRAM DATA .................... 85

C. INVESTIGATOR INDEX . . . . . . . . . . . . . . . . . 87

D. INSTITUTIONAL INDEX . . . . . . . . . . . . . . . . . . . . . 89

E. FACSIMILE COVER SHEET . . . . . . . . . . . . . . . . . . 91 


\title{
DIVISION OF ADVANCED ENERGY PROJECTS
}

\author{
PROGRAM OVERVIEW
}

\section{CHARTER}

The Division of Advanced Energy Projects (AEP) provides support to explore the feasibility of novel, energy-related concepts that evolve from advances in basic research. These concepts are typically at an early stage of scientific definition and, therefore, are premature for consideration by applied research or technology development programs. The AEP also supports high-risk, exploratory concepts that do not readily fit into a program area but could have several applications that may span scientific disciplines or technical areas.

The Division provides a mechanism for converting basic research findings to applications that eventually could impact the Nation's energy economy. AEP does not support evolutionary research or large scale, demonstration projects. Technical topics include physical, chemical, materials, engineering, and biotechnologies. Projects can involve interdisciplinary approaches to solve energy-related problems.

\section{SCOPE}

Projects supported by the Division arise from unsolicited ideas and concepts submitted by researchers. The portfolio of projects is dynamic and reflects the broad role of the Department in supporting research and development for improving the Nation's energy outlook. FY 1994 projects include the following topical areas:

- Novel Materials for Energy Technology

- Renewable and Biodegradable Materials

- Exploring Uses of New Scientific Discoveries

- Alternate Pathways to Energy Efficiency

- Alternative Energy Sources

- Innovative Approaches to Waste Treatment and Reduction

\section{FUNDING}

Projects are supported for a specified period of time, which typically does not exceed three years. In Fiscal Year 1994, the average annual funding level for an AEP project was $\$ 299,000$ and the average funding period was slightly less than 36 months. It is 
expected that, following AEP support, each concept will be sufficiently developed and promising to attract further funding from other sources in order to realize its full potential.

\section{SUBMISSION GUIDELINES}

Unsolicited proposals can be submitted by universities, industrial organizations, non-profit research institutions, or private individuals. The Division also considers ideas or concepts submitted by researchers at national laboratories.

\section{PREPROPOSALS}

Before a formal proposal is prepared, the proposer should submit a summary (3-5 pages) of the proposed work to the Division for consideration. The summary should be sufficiently detailed to enable an informed decision as to whether the proposed work would be programmatically suited to the charter of the Division of Advanced Energy Projects. It should include descriptions of the proposed method and its potential benefit to energy. The summary should also contain estimates of the funding period and of the annual funding level. If possible, some discussion of anticipated follow-on funding options should be provided.

\section{PROPOSALS}

After an AEP programmatic interest has been established, a proposal must be submitted consistent with the guidelines specified in the document, DOE/ER-0249, "Application Guide for the Office of Energy Research Financial Assistance Program - 10 CFR Part 605." Each proposal must contain:

- A cover page.

- A 200-300 word abstract describing the essence of the project.

- A technical discussion of the proposed concept and a description of the proposed work. While the discussion should be brief, there is no formal limitation on the number of pages allotted to this section of the proposal. Since this section provides the basis for the evaluations by technical reviewers, the proposer should make certain to adequately cover all aspects of the proposed project that are relevant to forming a judgment of the projects overall merit.

- A statement of work specifying all tasks to be performed in the course of the proposed work. (See Appendix A.)

- Description of available facilities. 
- Resumes of key personnel.

- Statement of all current and pending support for proposed and related research, and a description of research support for all projects that involve the principal investigator(s) and the period of time devoted to each project.

- A cost estimate for the proposed effort.

\section{PROPOSAL EVALUATION}

Awards are based on the results of an evaluation process which includes independent reviews by external scientific and technical experts. Regardless of the outcome of the evaluation, proposers receive copies of reviewers' reports.

Questions asked of the reviewers depend on the subject of the proposal, but usually include the following:

1. What is the scientific and technical merit of the proposed effort?

2. Is the proposed concept new? How does it compare with other work in the field?

3. Are there basic flaws or major shortcomings in the scientific or technical arguments underlying the concept?

4. Are the technological and/or material requirements associated with the proposed concept within present or near term capabilities?

5. Is there anything about the concept that makes its economics manifestly untenable, even under reasonably optimistic assumptions?

6. Is the anticipated benefit to the public high enough to warrant the Department of Energy's involvement in the R\&D effort?

7. How well does the proposed research match the AEP charter? 


\section{FURTHER INFORMATION}

Inquiries should be directed to:

Dr. Walter M. Polansky, Director

Division of Advanced Energy Projects

U.S. Department of Energy

ER-16, GTN

Washington, D.C. 20585

Phone: $\quad 301-903-5995$

Fax: $\quad$ 301-903-6067

(Facsimile cover sheet

given in Appendix E)

walt.polansky@MAILGW.ER.DOE.GOV

Deliveries must be addressed as follows:

Sue Ellen Stottlemyer

Phone: $\quad 301-903-5995$

U.S. Department of Energy

ER-16, GTN

19901 Germantown Road

Germantown, MD 20874

This book was compiled by Sue Ellen Stottlemyer. 


\section{SUMMARIES OF PROJECTS ACTIVE IN FY 1994}

\section{GRANT AND LABORATORY PROGRAMS}

There were 53 research projects in the Division of Advanced Energy Projects during Fiscal Year 1994 (October 1, 1993 - September 30, 1994). Thirteen projects were initiated during that fiscal year. Further information on a specific project may be obtained by contacting the principal investigator. See Appendix B for information on actual FY 1994 funding levels.

\section{Alfred University \\ Alfred, NY 14802}

1. Combustion Synthesis and Engineering of Nanoparticles for Electronic, Structural and Superconductor Applications

Gregory C. Stangle, School of Ceramic Engineering 607/871-2798

Funding Profile

Date Started: November 1, 1992

FY 93 - $\$ 225,000$

Anticipated Duration: 3 Years

FY $94-\$ 186,000$

FY $95-\$ 196,000$

Ultrafine particles are currently difficult to produce in commercial quantities and to use in the development of dense materials with precisely controlled microstructures. The investigation will: 1) produce nanoparticles of multicomponent oxide ceramic materials by a combustion synthesis technique that is readily scaled up; 2) apply proven, in-house grain-boundary engineering methods to fine-tune microstructure evolution during densification; 3) use conventional and rapid sintering techniques to densify consolidated nanoparticle compacts; and 4) characterize the material at each stage. Expected results include: a) the synthesis of nanoparticles of complex composition for use in several applications (such as $\mathrm{YBa}_{2} \mathrm{Cu}_{3} \mathrm{O}_{7-x}$, a high-temperature superconductor with uses, e.g., in magnetic flux trapping and high-speed capacitor applications; yttria-stabilized zirconia for, e.g., high surface toughness materials for high-temperature applications; and $\mathrm{BaTiO}_{3}$, a material expected to possess superparaelectric properties when nanocrystalline); b) the development and reduction to practice of a generic, widely applicable process; and c) the evaluation of the energy efficiency and commercialization potential of the process. The proposed study will be interdisciplinary, bringing together the areas of ceramic, electrical and chemical engineering, and will enlist three U.S.-based companies to aid in focusing the research toward the commercialization of successful research results. 


\section{Ames Laboratory lowa State University \\ Ames, IA 50011-3020}

\section{Magnetic Refrigeration for Sub-Room Temperature Cooling}

Karl A. Gschneidner, Jr., Metallurgy and Ceramics Division 515/294-7931

Funding Profile

Date Started: April 15, 1994

FY 94 - $\$ 360,000$

Anticipated Duration: 3 Years

FY $95-\$ 296,000$

FY $96-\$ 310,000$

The design of a new type of near-room temperature magnetic refrigerator and the demonstration of its technical feasibility as an alternative refrigeration technology for energy-intensive industrial and commercial refrigeration systems is under development. Large-scale (>30 kW chlorofluorocarbon (CFC) vapor) cycle refrigeration units in commercial facilities, such as deep-freezers in meat packing plants and display case chillers in supermarkets, represent a significant portion of the total U.S. electrical energy demand. The efficiency of existing refrigerators is considerably less than that of the ideal Carnot efficiency because of intrinsic limitations of the currently used vapor cycle process, especially in the compression and Joule-Thomson expansion parts of the cycle. In contrast, the magnetic refrigeration cycle has a very high intrinsic efficiency; the efficiency appears to be limited by factors susceptible to control, such as non-ideal materials properties, parasitic heat transfer, and flow losses. Replacement of vapor cycle refrigerators with magnetic refrigerators offers a significant potential energy savings. In addition, magnetic refrigerators do not require any ozone-damaging CFCs or other volatile fluids that have a significant greenhouse effect, so their widespread use would reduce potential environmental hazards. The elimination of CFCs is also in compliance with federally mandated programs to reduce the risk to the ozone layer. There are two major aspects of this project. The first is a materials development task, which will be carried out by the Ames Laboratory in Ames, lowa. The second task involves the engineering aspects of designing, constructing, and demonstrating a sub-room temperature active magnetic regenerator magnetic refrigerator, which will be carried out at the Technology Center of the Astronautics Corporation of America, in Madison, Wisconsin. 


\section{Ames Laboratory}

Ames, IA 50011

\section{Design of Materials with Photonic Band Gaps}

Kai-Ming Ho, Institute for Physical Research and Technology 515/294-1960

Funding Profile

Date Started: February 15, 1992

FY 92 - $\$ 299,000$

Anticipated Duration: 3 Years

FY $93-\$ 314,000$

FY $94-\$ 297,000$

This joint theoretical and experimental program is intended to design, fabricate and characterize a new class of composite materials which possess forbidden ranges of frequencies, in which electromagnetic waves cannot propagate in any direction. These materials are called "photonic crystals" and the forbidden frequencies are called "photonic gaps", and they can be regarded as photonic analogues of electronic semiconductors with electronic gaps. This class of material will exhibit many interesting physical properties, and will find important practical applications in lasers, mirrors, resonators, filters, and quantum optical devices. The theoretical effort will be directed at designing periodic dielectric structures that give the optimal frequency gap for various applications with special emphasis on the fabricability of these structures, especially in the sub-micron length scale where these materials will find applications in optical measurements. The main purpose of the experimental effort is to fabricate the structures designed by theory in the micron and sub-micron length scales, using micro-fabrication patterning and siching techniques. The structural and optical properties of these micro-structures will be characterized and studied using optical techniques. The effect of disorder, defects and structural imperfections on the propagation of electromagnetic waves through these photonic crystals will also be studied both theoretically and experimentally. 


\section{Argonne National Laboratory 9700 South Cass Avenue \\ Argonne, IL 60439}

\section{Application of Aqueous Biphasic Extraction to Radioactlve Waste Treatment*}

David S. Chaiko, Chemical Technology Division

$708 / 252-4399$

Funding Profile

Date Started: December 1, 1990

FY $91-\$ 475,000$

Anticipated Duration: 3 Years

FY $92-\$ 485,000$

FY $93-\$ 495,000$

Aqueous biphase extraction systems will be developed as a means of treating radioactive wastes. The separation concept involves the selective partitioning of either solutes or colloid-size particles between two immiscible aqueous phases. Wet grinding of plutonium residues to an average particle size of one micron will be used to liberate the plutonium from the bulk of the particle matrix. The processing goal is to produce a plutonium concentrate that will more effectively integrate with existing and developing chemical recovery processes. Coupling physical beneficiation with chemical processing will result in a substantial reduction in the volume of mixed wastes generated from dissolution recovery processes. As a part of this project, applications of aqueous biphase extraction will be explored that include the separation and recovery of dissolved species such as metal ions and water-soluble organics.

"Project Completed 


\section{Argonne National Laboratory 9700 South Cass Avenue Argonne, IL 60439}

\section{High-Flux, Large-Area Carbon-Cluster Beams for Thin-Film Deposition and Surface Modification}

Dieter M. Gruen, Materials Science Division

708/252-3513

Funding Profile

Date Started: March 15, 1992

FY 92 - $\$ 445,000$

Anticipated Duration: 3 Years

FY $93-\$ 400,000$

FY $94-\$ 255,000$

The discovery of the fullerenes, and particularly of $C_{60}$, buckminsterfullerene, is an important scientific development. These kinetically stable carbon cluster molecules, allotropes of carbon, are in fact thermodynamically unstable with respect to diamond and graphite by $\sim 5 \mathrm{kcal} / \mathrm{mol} \mathrm{C}$. The fact that $\mathrm{C}_{60}$ has a vapor pressure of $\sim 10^{-3}$ Torr at $500^{\circ} \mathrm{C}$ opens up the possibility of generating high-flux, high-energy carbon-cluster ion beams for thin-film deposition (including diamond films) and surface modification. A microwavedriven electron cyclotron resonance (ECR) plasma source will be used to generate the fullerene ion beams. The ECR source combines high-ionization efficiency with lowelectron temperatures $(5-10 \mathrm{eV})$. Typical ion current specifications for argon are 30 $\mathrm{mA} / \mathrm{cm}^{2}$ with a uniformity of $\pm 5 \%$ over a $4 "$ diameter area. The mass transport associated with a similar current of singly ionized $C_{60}$ would correspond to 150 amps of atomic ions. The substrate impact energy will be controlled independently of the plasma parameters by biasing the substrate. End-Hail optics will be combined with the ECR plasma to provide additional control of beam characteristics. The ECR facility will be used to synthesize and characterize, by a variety of techniques, diamond films, diamondlike films, and carbon-implanted layers on large areas with high-deposition rates. The effort is directed toward producing high-quality films at low-substrate temperatures in a manner that can be adapted to industrial processes. 


\section{Argonne National Laboratory \\ 9700 South Cass Avenue \\ Argonne, IL 60439}

\section{New Ion Exchange Materials for Environmental Restoration and Waste Management*}

E. Philip Horwitz, Chemistry Division

$708 / 252-3653$

Funding Profile

Date Started: December 1, 1990

FY 91 - $\$ 440,000$

Anticipated Duration: 3 Years

FY 92 - $\$ 430,000$

FY $93-\$ 435,000$

The objective of this program is to synthesize, characterize, and evaluate a new class of cation exchange resins. The new resins will contain the geminally substituted diphosphonic acid functional group. Ion exchange resins containing geminally substituted diphosphonic acid groups should have vastly superior properties compared to commercially available cation exchange resins and should find wide-scale applications in environmental restoration (e.g., groundwater cleanup) and in waste management (e.g., minimization of waste volume). Alkyl-1,1-diphosphonic acids are among the most powerful complexing agents for polyvalent metal ions in aqueous solution, particularly at $\mathrm{pH}<2$. But, heretofore, it has not been possible to synthesize resins containing diprosphonic acid groups, because of the difficulty of introducing this group into a preformed polymer matrix. The synthesis of resins with the diphosphonic acid groups will be accomplished by the polymerization of vinylidene-1,1-diphosphonic acid (VDPA) or by the copolymerization of VDPA with suitable comonomers (e.g., acrylamide/bis-acrylamide or styrene/divinylbenzene). This approach represents a major departure from the traditional methods for preparing ion exchange materials whereby the exchangeable functional groups are introduced onto a preformed polymer matrix.

"Project Completed 


\section{Argonne National Laboratory 9700 South Cass Avenue \\ Argonne, IL 60439}

\section{Development of an Ion Replacement Electrorefining Method}

Zygmunt Tomczuk, Chemical Technology Division

708/252-7294

Funding Profile

Date Started: February 15, 1992

FY 92 - $\$ 450,000$

Anticipated Duration: 3 Years

FY $93-\$ 450,000$

FY $94-\$ 450,000$

The objective of this project is to investigate promising methods for carrying out a new metal separation and purification process called ion replacement electrorefining. The challenge and program focus lie in developing a counter electrode that can serve in a sequential and, if possible, reversible manner as a cathode during metal dissolution and an anode during metal separation/deposition. The development work will be conducted with a view toward one particularly important application - the separation of spent metallic nuclear reactor fuel (or any nuclear waste material in metallic form) into its elemental constituents. The key goal is to produce a clean separation between actinide and nonactinide elements. One potential use for the ion replacement electrorefining method is the reprocessing of spent metal fuel from an Integral Fast Reactor (IFR), but it is also adaptable to the separation of transuranic elements from spent fuel and waste generated by the light water nuclear reactor (LWR) industry and the defense nuclear programs. In the case of the IFR, the proposed process represents an attractive alternative towards commercialization, in the sense that it offers a simplification of the conventional pyrometallurgical electrorefining process under development within the IFR Program. For LWR and defense waste applications, the ion replacement electrorefining method could be used in conjunction with processes that incorporate reduction of actinide element compounds (usually oxides) to a metallic form. 


\section{Argonne National Laboratory 9700 South Cass Avenue \\ Argonne, IL 60439}

\section{Ultrafast Molecular Electronic Devices* \\ Michael R. Wasielewski, Chemistry Division 708/252-3538}

Date Started: October 1, 1991

Anticipated Duration: 3 Years
Funding Profile

FY 92 - $\$ 445,000$

FY $93-\$ 425,000$

FY $94-\$ 405,000$

The objective of this project is to apply the fundamental chemistry of ultra-fast photoinitiated electron transfer reactions to produce high speed, energy efficient molecular electronic devices. These molecules will act as opto-electronic switches on a picosecond time scale. The molecular switches are designed around electron donor-acceptor molecules that possess well-defined, easily controlled structures. Photo-excitation of these molecules with visible light results in very efficient charge separation reactions that set the on or off state of the molecular switch. Two types of molecular switch will be developed. The first type is a bistable electron transfer switch which will use a light pulse of one color to store information in the solid state in the form of a long-lived charge separation, and a light pulse of a second color to recover it. The second type of switch is a field effect switch which will use the electric field generated by one charge separated electron donor-acceptor pair to influence the on or off state of a second donor-acceptor pair. These switch molecules will be assembled in ordered arrays on surfaces using selfassembled monolayer and liquid crystal polymer technology to produce electro-optic devices. Potential applications of this technology are optical computing, wavelength selective gates and switches, laser detectors, electro-optic devices, modulators, and memories.

*Project Completed 


\section{University of Arizona \\ Tucson, AZ 85721}

\section{Creation and Destruction of $C_{B 0}$ and Other Fullerene Solids}

Donald R. Huffman, Department of Physics

602/621-4804

Funding Profile

Date Started: March 1, 1993

FY $93-\$ 302,000$

Anticipated Duration: 3 Years

FY $94-\$ 301,000$

FY $95-\$ 302,000$

This work will focus on the creation and destruction of fullerenes, for the purposes of producing new materials of interest to the Department of Energy. It is now known that, besides the famous $C_{60}$ molecule (buckminsterfullerene), hundreds of other fullerenes, with masses of up to 600 carbon atoms, are also synthesized in the Krätschmer-Huffman process. The physics underlying the creation of the fullerenes is poorly understood and the major portion of this work will be a systematic study of the process. This will involve construction of a new, fully-instrumented smoke-chamber, that will be used in a methodical exploration of fullerene yield versus production conditions. Mass-spectral analysis will be an indispensable part of this study. As part of the work, an existing timeof-flight mass-spectrometer at the University of Arizona will be upgraded for optimum performance with fullerene samples. Recent reports of the successful seeding of CVDgrown diamond films using thin films of $C_{70}$, and of the room-temperature conversion of solid $\mathrm{C}_{60}$ into diamond powder via non-hydrostatic compression, indicate that some of the first important commercial applications of the fullerenes may involve their destruction as a means of synthesizing high-performance materials. The second major portion of this work will be a systematic study of the destruction and modification of the various fullerenes by chemical reaction, electromagnetic radiation, and electron bombardment. Transmission electron-microscopy (TEM) and electron-energy-loss spectroscopy (EELS) will be very valuable in analyzing the results of these destructive tests, and a portion of the proposed funding will support this work at a TEM / EELS facility located at the University of Arizona. 


\section{Brookhaven National Laboratory Upton, NY 11973}

\section{Energy Related Applications of Cluster Impacts* \\ Lewis Friedman, Chemistry Department $516 / 282-4325$}

Date Started: April 1, 1991

Anticipated Duration: 3 Years
Funding Profile

FY $91-\$ 440,000$

FY $92-\$ 585,000$

FY $93-\$ 490,000$

The impacts of accelerated cluster ions on solid surfaces generate transient highly compressed assemblies of energetic atoms. These atomic assemblies are unique in that very large amounts of energy are concentrated in the motion of the atoms rather than in the atomic electrons so that cooling processes are slower than with systems heated by lasers, electron beams or high-velocity ion beams. The direct deposition of energy into the motion of target atoms produces a non-random directional distribution of translational energy in the target atoms. As a consequence, a very small fraction of the target atoms may acquire sufficient translational and/or vibrational energy to drive nuclear fusion reactions. A study of the effects of cluster impacts on solid surfaces in economical laboratory scale experiments can illuminate mechanisms of the ablative processes normally relied upon to compress and heat plasmas in inertially confined fusion. In addition, the direct application of cluster beams in place of heavy ion beams to heat inertially confined plasmas can be investigated. Most of the proposed experimental work will build on the foundation already established in studies of fusion reactions induced by singly-charged accelerated cluster ions. Studies will focus on the exploitation of multicharged ions to extend the range of velocities and sizes of the projectiles used to initiate cluster impact phenomena. The major objectives of this project are to study the properties of condensed matter under extreme conditions of pressure and energy density and to evaluate the potential of cluster impacts for use in the economical development of fusion energy.

*Project Completed 


\section{Brooklyn College of City University of New York Brooklyn, NY 11210}

\section{Solar Detoxification of Aquatic Systems With Porous Photocatalysts}

Micha Tomkiewicz, Physics Department

718/951-5357

Funding Profile

Date Started: November 15, 1991

FY $92-\$ 118,000$

Anticipated Duration: 3 j'ears

FY $93-\$ 127,000$

FY $94-\$ 131,000$

The objective of this project is two fold: (a) To investigate the feasibility of using a porous structure of a side bandgap semiconductor as a portable photocatalyst for photodegradation of organic pollutants in an aqueous environment; and (b) establish the correlation between the morpholugy of the porous photocatalyst and its efficiency in the photocatalytic process. Initially, efforts will be concentrated on the photocatalytic decomposition of two classes of organic materials: (a) Hydrocarbons, both light aliphatic and light aromatics, such as benzene and toluene. This work will be aimed primarily at water decontamination due to oil spills. (b) Salicylates. These are soluble ionic compounds that are being proposed in some quarters to serve as standards for the efficiency of various water purification schemes. The initial choices for the photocatalyst are porous $\mathrm{TiO}_{2}$ films or beads that will be prepared either by the sol-gel method or by thermal decomposition of organic titanates, to make them low density enough to float in an aqueous environment. The principal tools in analyzing the porosity and the pore structure will be image processing in conjunction with optical and electron microscopies, small-angle $x$-ray scattering and impedance measurements. The reactants and the reaction products will be analyzed by absorption spectroscopy, by gas and liquid chromatography, and by electrodes specific to oxygen and carbon dioxide. Slow kinetic studies will be conducted by monitoring the time evolution of disappearance of the reactants and appearance of the products. Kinetic studies on a faster time scale will be conducted by flash-photolysis absorption measurements and time resolved luminescence. Parallel to the experimental work, computer simulations of the photocatalytic process on random porous photocatalysts and on porous deterministic fractals will be conducted. 


\section{University of California, Los Angeles \\ 405 Hilgard Avenue \\ Los Angeles, CA 90024}

\section{Experimental, Theoretical and Computational Study of Frequency Upshift of Electromagnetic Radiation Using Plasma Techniques}

Chan J. Joshi, Electrical Engineering Department 310/825-7279

Funding Profile

Date Started: January 15, 1991

FY 91 - $\$ 250,000$

Anticipated Duration: 4 Years*

FY $92-\$ 250,000$

FY $93-\$ 250,000$

In this project, a new class of coherent electromagnetic radiation generation devices that, in principle, can cover the range of frequencies from microwaves to the vacuum ultraviolet, will be investigated both theoretically and experimentally. In this method the frequency of the incident $e . m$. wave is upshifted by suddenly lowering the refractive index of the medium through which the wave is propagating. This can be done by rapidly ionizing the medium and forming a plasma. Various regimes will be investigated: (a) Spatially uniform ionization (or flash ionization). If the source wave $\left(\omega_{\mathbf{s}}, \mathrm{k}_{\mathbf{8}}\right)$ is propagating through a medium that is uniformly ionized in time, then the wavenumber of this source wave $k_{s}$ is fixed, but the frequency can change to $\omega=\sqrt{\omega_{s}^{2}+\omega_{p}^{2}(t)}$ where $\omega_{p}$ is the plasma angular frequency. This technique is particularly useful for generating tunable e.m. radiation in the $\mathrm{mm}$ wave range. (b) Frequency upshift by a moving ionization front. By sending an ionization front, it is also possible to upshift the source wave frequency. If the plasma is underdense in the fronts frame, the upshifted frequency is $\omega=\omega_{s}\left(1+\frac{\omega_{p}^{2}}{4 \omega_{s}^{2}}\right)$. If the plasma frequency is greater than the source frequency, this technique can generate frequency upshifts that are much greater than the flash ionization technique. This technique is suited to generate far-infrared and infrared radiation. An applications study will also be undertaken to identify technologies which would likely be impacted by these sources.

*Includes 12 month no-cost extension 


\section{University of California, Los Angeles 405 Hilgard Avenue \\ Los Angeles, CA 90024}

\section{Synchronous Picosecond Sonoluminescence: Developing and Characterizing a New Light Source}

Seth J. Putterman, Department of Physics

310/825-2269

Funding Profile

Date Started: December 15, 1991

FY 92 - $\$ 388,000$

Anticipated Duration: 3 Years

FY $93-\$ 275,000$

FY $94-\$ 194,000$

It has recently been discovered at the UCLA acoustics laboratory that the passage of a sound wave through a liquid leads to the ultra-precise clock-like emission of flashes of light. The power of the individual flashes is greater than 1 milliwatt and their width is less than 100 picoseconds. This effect is due to a spontaneous yet controllable concentration of sound energy by a factor of one trillion. The goal of this project is to perform those measurements which will elucidate the mechanism responsible for this off-equilibrium phenomenon (that has been named synchronous picosecond sonoluminescence). Toward this goal, the time and spatial resolution of the flashes will be measured along with the time development of the spectrum. Correlations and possible coherence will be searched for in the radiated light. Efforts will be made to measure the spectrum of microwave, radio frequency and far ultra-violet radiation. The degree of synchronicity will also be probed. These efforts will lead to the development of a variable width, variable intensity picosecond light pulser. By understanding the novel cooperative effects that cause synchronous picosecond sonoluminescence, insight will be gained as regards the means whereby large controllable energy concentrations could be achieved in other systems. 


\section{University of California, Santa Barbara}

\section{Santa Barbara, CA 93103}

\section{Photo-Induced Electron Transfer From a Conducting Polymer to Buckminsterfullerene: A Molecular Approach to High Efficiency Photovoltaic Cells}

Paul Smith, Materials Department 805/893-8104

Funding Profile

Date Started: August 15, 1993

FY $93-\$ 171,000$

Anticipated Duration: 3 Years

FY $94-\$ 283,000$

FY $95-\$ 446,000$

The recently-discovered photoinduced electron transfer, with subpicosecond transfer rate, in composites of a conducting polymer, MEH-PPV, and a molecular acceptor, buckminsterfullerene, $\mathrm{C}_{60}$, opens a new direction and a new opportunity for photovoltaic research. Since the charge transfer takes place $\sim 1000$ times faster than the radiative and/or non-radiative decay of photoexicitations, the quantum efficiency for charge transfer and charge separation is near unity. Photoinduced electron transfer across the donoracceptor rectifying heterojunction offers potential for solar cell applications, using materials that exhibit a unique combination of properties: electronic and optical properties of semiconductors and metals in combination with the attractive mechanical properties and the processing advantages of polymers. The potential advantages of an all-polymer heterojunction solar cell include the following: low cost (literally fabricated from solution); large area; and flexible (components are polymers that can be solution cast onto polymer substrates). The goal of the proposed research is to build upon this novel molecular approach to photoinduced charge separation and charge transfer, with quantum efficiency approaching unity, and to create a research and development program that will enable the production of efficient, flexible, "plastic" solar cells that can be implemented in large areas. 


\section{University of Colorado \\ Boulder, CO 80309}

\section{Two-Dimensional Synthesls: Ultrathin Porous Membranes \\ Josef Michl, Department of Chemistry and Biochemistry 303/492-6519}

Funding Profile

Date Started: December 1, 1993

FY $94-\$ 300,000$

Anticipated Duration: 3 Years

FY $95-\$ 300,000$

FY $96-\$ 300,000$

The objective of this research program is to synthesize and characterize an ultrathin fishnet-like sheet, suitable for application in molecular separations. This will be a new kind of heat-resistant organic-inorganic solid with a regular repeating two-dimensional structure, containing openings of a predetermined size. The first step will be the synthesis of a tentacle-carrying pillar-like monomer with three arms opposite to the tentacled end. Next, its molecules will be constrained by strong adsorption of the tentacles to a liquid-liquid interface, oriented with the pillar perpendicular to the surface and the arms parallel to it, at a distance of a little less that $10 \AA$. In the subsequent step, the arms of the monomer molecules will be cross-linked in two dimensions into a sheet composed of a regular covalent hexagonal lattice parallel to the surface. The polymerization will be monitored in situ. The lateral dimensions of the sheet will be maximized by a search for optimum reaction conditions. Neighboring sheet segments will be stitched together with relatively flexible threads to yield a large macroscopic piece of ultrathin membrane. The tentacles will then be clipped off, permitting desorption and removal of the net-like membrane from the surface. The construction will be completed by additional cross-linking to form a second hexagonal lattice on the side that previously carried the tentacles. The two hexagonal nets will thus be bonded into a single sheet through pillars located at well separated trigonal connector centers. The sheet will be about 15 to $20 \AA$ thick, and will contain openings with a diameter of about $20 \AA$. The structure will be characterized by the techniques of surface science and its separatory properties will be tested. This will complete the proof-of-concept part of the project. The experience gained in the project will be used to design a second generation membrane for an actual industrial separation process, taking advantage of the flexibility available in the choice of the size of the openings, which can be chosen anywhere from nearly zero to about 40 to $50 \AA$ in diameter, and in the choice of chemical functionalities at the rim of the openings. 


\section{Colorado State University \\ Fort Collins, CO 80523}

\section{Capillary Discharge Extreme Ultraviolet Lasers*}

Jorge J. Rocca, Electrical Engineering Department $303 / 491-8371$

Funding Profile

Date Started: December 15, 1990

FY $91-\$ 170,000$

Anticipated Duration: 38.5 Months ${ }^{\star \star}$

FY $92-\$ 130,000$

FY $93-\$ 130,000$

The project objective is to explore the generation of sofi $x$-ray laser radiation in a capillary discharge. A hot and highly ionized plasma column with a large length-to-diameter ratio $(/ / d=10-100)$ will be generated by a rapid discharge into a capillary structure. A compact $800 \mathrm{kV}, 150 \mathrm{kA}$ pulser will provide the excitation. At the end of the current pulse, rapid cooling of the plasma is expected to occur as a consequence of electron heat conduction to the capillary walls and plasma radiation. Under optimized plasma conditions, collisional recombination of the capillary plasma is expected to lead to amplification at extreme ultraviolet and soft $x$-ray wavelengths. Experiments will be conducted to demonstrate gain, focusing first in the 3-2 transition of hydrogenic ions. The initial experiment will explore gain in the $18.2 \mathrm{~nm}$ transition of hydrogenic carbon in a polyethylene capillary. The proposed capillary laser scheme offers the potential for compact, simple and efficient soft $x$-ray laser sources.

*Project Completed

**Includes 2.5 month no-cost extension 


\section{General Electric Company \\ Schenectady, NY 12301-0008}

\section{Evaporation Through Tungsten to Achieve High-Rate Vapor Phase Processing of Intermetallics}

David W. Skelly, Corporate R\&D Center $518 / 38 T-6534$

Funding Profile

Date Started: January 15, 1994

FY 94 - $\$ 291,000$

Anticipated Duration: 3 Years

FY $95-\$ 291,000$

FY $96-\$ 318,000$

The understanding of high-rate electron beam evaporation synthesis derived from this investigation will have significant impact on the ability to fabricate advanced designs of turbine blading, designs which cannot be produced by any state-of-the-art technology. Success in this program will make possible forming the complex cooling structure after the casting process, followed by a thin outer skin deposited by electron beam (EB) evaporation to create a double-wall. This structure combined with composite materials developed specifically for the EB process, will provide long term efficiency improvements and enhanced service life. High-rate EB evaporation processes are currently difficult to control for deposition of complex alloys and intermetallics: fluctuations in power level and beam position can lead to large fluctuations in deposition rate and deposit chemistry. Modification of current practice of EB processes has been found to enhance chemistry uniformity and deposition rates through the addition of tungsten to the evaporation pool to permit much higher pool temperatures and stable pool dynamics. The objective of this research is to define optimum operating conditions for achieving economic deposition of controlled-chemistry, controlled-thickness Ni-base superalloys, NbTi-base metallic materials, and high strength, high temperature intermetallic phases. The approach will be to: evaluate process stability during prolonged evaporation through a tungsten-rich liquid pool; measure the effect of tungsten concentration in the pool on the evaporation process; characterize the influence of electron beam scan rate and scan pattern on the deposit chemistry and deposition rate; characterize the influence of the source temperature profile on deposit chemistry and deposition rate; determine evaporation conditions for $\mathrm{Ni}$-base alloys containing $\mathrm{Ta}$ and $\mathrm{Mo}$; and extend the electron beam evaporation-through-tungsten processing to higher melting intermetallic phases and $\mathrm{NbTi}$ base metals. 


\section{University of Houston \\ Houston, TX 77204-5502}

\section{Research on Magnet Replicas and the Very Incomplete Melssner Effect*}

Roy Weinstein, Institute for Particle Beam Dynamics

713/743-3600

Funding Profile

Date Started: January 15, 1991

FY $91-\$ 351,000$

Anticipated Duration: 3 Years ${ }^{\star *}$

FY $92-\$ 341,000$

The aim of this project is to produce permanent magnets comprised of superconductors (SCs) that work at or near liquid nitrogen temperatures $(77 \mathrm{~K})$. These magnets show promise for applications in motors, generators, charged particle beam steering, industrial particle separators, MRI, and other constant field applications. One advantage of these magnets is that much higher fields are possible than for ferromagnets. A second is that the SC magnets can accurately copy the fields used to activate them, thus making possible magnet replicas. In addition, SC magnets are lighter than iron, cost less than an electromagnet, and consume negligible energy. The SC magnet replicas are made of bulk pieces of high temperature superconductor, and so do not require the availability of wire, which is difficult to produce from these materials. Both chemical and radiation methods are being used to produce materials capable of storing high field. Stored fields have been increased by factors of over 1,000 in the past two years. Presently, stored fields in $1 \mathrm{~cm}^{3}$ samples are already three-times stronger than samarium-cobalt magnets. Methods of improving stability have been found. A small motor has been run using a magnet replica.

\footnotetext{
"Project Completed

**Includes 12 month no-cost extension
} 


\section{University of Illinois at Chicago}

\section{Chicago, IL 60680}

\section{Molecular Design Concept for X-Ray Laser Research* \\ Charles K. Rhodes, Department of Physics \\ 312/996-4868}

Funding Profile

Date Started: December 15, 1990

FY $91-\$ 300,000$

Anticipated Duration: 3 Years

FY 92 - $\$ 300,000$

FY $93-\$ 300,000$

The goal of the project is the construction of an x-ray laser in the kilovolt regime. Recent experimental results indicate that a new technique for the generation of strong amplification of $x$-ray wavelengths is feasible. It involves the combination of (a) a new ultrahigh brightness subpicosecond laser technology; and (b) a recently discovered unique mode of strong-field interaction, particularly applicable to molecules. A concept of molecular $x$-ray laser design emerges from these considerations that matches the mode of excitation to the structure of the molecular system. The molecular approach enables the combination of very highly electronically excited conditions with an environment characteristic of dense cold matter, a general situation exceptionally conducive to x-ray amplification. Both high efficiency and wavelength tunability are intrinsic features of this method. A program of research is being conducted to evaluate this method for the production of $\mathrm{x}$-ray amplification in the kilovolt region.

"Project Completed 


\section{Johns Hopkins University \\ Baltimore, MD 21218}

\section{Ultrasonic and Dielectric NonInvasive Dlagnostics for Sintering of Ceramic Composites}

Moshe Rosen, Materials Science Department

410/516-8678

Funding Profile

Date Started: December 1, 1993

FY $94-\$ 358,000$

Anticipated Duration: 3 Years

FY $95-\$ 342,000$

FY $96-\$ 290,000$

The potential advantages of using microwaves to process ceramics have been recognized for more than three decades. However, only during the last several years, the scientific and engineering communities have experienced an oulburst of research in this area. Nevertheless, a profound understanding of how materials interact with microwaves during sintering is still lacking. Measurement of the dielectric and mechanical properties of a material during microwave processing in real-time can provide the necessary theoretical and experimental insight into understanding this interaction that can subsequently be applied for the optimization of microwave processing of materials. In the course of this project, in situ, nonintrusive diagnostics for microwave sintering of ceramic materials will be ds eloped. The essence of the project is a specially designed system for ultrasonic and dielectric probes to be integrated within the microwave furnace. The ultrasonic data can be ultimately related to the densification process during sintering of ceramics, while the dielectric characteristics are connected to the absorption mechanism of the microwave energy by the ceramic material. Acquisition of such data during sintering will shed light on the sintering kinetics and its mechanism and, consequently, provide an understanding of the optimal sintering conditions needed to achieve maximum densification and the desired material properties. Furthermore, such data can be instrumental in developing predictive models for microwave sintering of ceramic materials. 


\section{Lawrence Berkeley Laboratory Berkeley, CA 94720}

\section{Compact MeV Ion Implanter}

Simone Anders, Plasma Applications Group 510/486-6745

\section{Funding Profile}

Date Started: February 15, 1994

FY 94 - $\$ 294,000$

Anticipated Duration: 3 Years

FY $95-\$ 300,000$

FY $96-\$ 298,000$

A new kind of $\mathrm{MeV}$ ion implanter will be developed, the distinguishing features of which will be its relatively small size and low cost. The heart of the device will be a novel kind of ion source by means of which high charge state ions will be produced, thereby allowing the production of high energy ion beams ( $1 \mathrm{MeV}$ and above), using only modest accelerating voltages (one to several hundred $\mathrm{kV}$ ). The ion source will be a repetitively pulsed vacuum spark source, and the implantation facility will thus also generate repetitively pulsed, large area, metal ion beams. By virtue of the relatively low voltages employed the implanter will be much more compact and of much lower cost than present state-of-the-art facilities which employ singly charged ions and megavolt power supplies. From the perspective of new physics, a novel kind of ion source will be developed vacuum arc ion sources have been developed but not vacuum spark ion sources, and it is in the latter that the highly stripped ions are to be found, yielding high energy at modest voltage. From the perspective of new technology, this is an entirely new approach to doing MeV ion implantation, making high energy surface modification techniques feasible for a vastly broader field of users than at present. 


\section{Lawrence Berkeley Laboratory \\ Berkeley, CA 94720}

\section{Metallic Multilayer and Thin Film Fabrication*}

Ian G. Brown

510/486-4174

Funding Profile

Date Started: April 1, 1991

FY $91-\$ 288,000$

Anticipated Duration: 3 Years

FY $92-\$ 337,000$

FY $93-\$ 270,000$

The application of pulsed metal plasma gun techniques to the fabrication of metallic superlattices, multilayers and thin films will be investigated. Multilayer structures will be synthesized that are of relevance to $x$-ray optical devices, to magnetic and magnetooptical recording media, and to the fabrication of high temperature superconducting thin films. The quality and characteristics of the thin film structures formed in this way will be explored. This means of fabrication of metallic multilayer systems is new and has not yet been examined except in preliminary testing at this laboratory. At the same time, interest in artificial metallic superlattices from a fundamental scientific perspective, and in metallic multilayer structures from the standpoint of applied technology, is growing rapidly. It is important to explore and develop the application of this new technique to these fields. The proposed program will make immediate application of the method within the three fields mentioned above ( $x$-ray optics, magneto-optics and superconducting thin films) via collaborations with materials science research groups at this laboratory.

*Project Completed 


\section{Lawrence Berkeley Laboratory \\ Berkeley, CA 94720}

\section{Cyclotron Mass Spectrometer for Tracer Studies* \\ Ka-Ngo Leung \\ 510/486-5011}

Date Started: April 1, 1991

Anticipated Duration: 3 Years
Funding Profile

FY $91-\$ 290,000$

FY $92-\$ 245,000$

FY $93-\$ 225,000$

A compact research cyclotron will be developed which uses permanent magnets and axial ion injection. The new instrument will be used as an ultrasensitive accelerator mass spectrometer (AMS) for applied tracer studies. This device can take the place of bulky, cumbersome and much more expensive tandem Van de Graaff accelerators usually employed in AMS applications and, in fact, can be made "portable". Thus, this new machine has the potential for great practical benefit primarily by permitting detection or monitoring of minute quantities of hazardous substances and contaminants in exhausts and effluents. Moreover, the instrument is predicted to have sufficient sensitivity to detect ${ }^{14} \mathrm{C}$ isotopes as tracers after enormous dilution, opening the door to a large variety of environmental, biomedical, and archeological applications. To facilitate ${ }^{14} \mathrm{C}$ tracer work, the effort also includes optimization of a $\mathrm{C}^{-}$ion source that uses gaseous $\mathrm{CO}$ or $\mathrm{CO}_{2}$ instead of solid graphite sputtering. It is expected that at the end of the project, the cyclotron mass spectrometer system will be developed well enough and its utility demonstrated to permit transfer to industry.

*Project Completed 


\section{Lawrence Berkeley Laboratory Berkeley, CA 94720}

\section{Blue-Emitting Devices Based on Gallium Nitride}

Michael D. Rubin, Energy and Environment Division 510/486-7124

Funding Profile

Date Started: May 15, 1994

FY $94-\$ 319,000$

Anticipated Duration: 3 Years

FY $95-\$ 340,000$

FY $96-\$ 332,000$

The purpose of this project is to convert the recent breakthroughs in growth of gallium nitride (GaN) into practical ultraviolet and blue light emitting diodes and lasers. This technology is critical to national competitiveness in the development of the next generation of optoelectronic devices. Short-wavelength semiconductor devices based on GaN are needed for many important applications such as energy-efficient illumination, high-density optical data storage, flat-screen color displays, underwater communications, and high-temperature electronics. GaN is a III-V semiconductor with a direct bandgap of $3.4 \mathrm{eV}$ in the ultraviolet. One of the principal technical problems that limits device applications has been achieving controllable properties with addition of $\mathrm{Mg}$. The nitrogen concentration of the films was greatly increased, by using a reactive ion-beam process, thus eliminating the primary background defect concentration. Upon attaining threshold levels of conductivity and mobility, it was discovered that good quality material could be readily obtained by a variety of doping methods including ion implantation, diffusion and co-evaporation of $\mathrm{Mg}$. The defect studies which guide the improvements in the growth process will be continued. This process, along with specialized ion beam technology, will be transferred to Hewlett-Packard where it will be reproduced in a large-scale commercial growth system. Simultaneously, fabrication of light-emitting devices will begin, using current materials, in cooperation with Hewlett-Packard. 


\section{Lawrence Livermore National Laboratory Livermore, CA 94550}

\section{Pulsed Plasma Processing of Effluent Gases}

J. N. Bardsley

510/422-6008

Date Started: July 10, 1992

Funding Profile

Anticipated Duration: 3 Years

FY 92 - \$222,000

FY 93 - $\$ 108,000$

FY 94 - $\$ 330,000$

FY $95-\$ 330,000$

A study will be carried out of the science underlying the use of pulsed electrical discharges for the simultaneous removal of $\mathrm{NO}_{\mathrm{x}}, \mathrm{SO}_{2}$ and soot from diesel engine exhausts. The goals involve major advances in the understanding of breakdown mechanisms in coronal discharges, the elucidation of the chemical reaction schemes responsible for the conversion of the pollutants to benign molecules, experimentation with novel devices, preliminary analysis of the scaling laws, and economic and environmental considerations relevant to the transfer of this technology from the laboratory. The research will be performed by a multidisciplinary team from the Physics, Electrical Engineering, and the Chemistry and Materials Science Departments. 


\section{Lawrence Livermore National Laboratory Llvermore, CA 94560}

\section{Solid State Multi-Layered Batterles}

Richard M. Bionta

510/423-4846

Funding Profile

Date Started: October 15, 1993

FY $94-\$ 419,000$

Anticipated Duration: 2 Years

FY $95-\$ 296,000$

The purpose of this project is to develop and study thin film solid-electrolyte batteries fabricated by the advanced multilayer sputtering techniques developed for $x$-ray optics. This technique allows the battery to be constructed in situ by depositing the anode, electrolyte, and cathode as distinct layers with several computer controlled magnetron sputtering sources. Solid-electrolyte batteries have long been attractive because of their shelf-life and compatibility with severe environments. The discovery of new materials for cell construction has resulted in increased solid state battery research. Recently, rechargeable lithium cells that operate at ambient temperature have been developed based on ionically conducting solid polymer electrolytes. This project will concentrate on the development of thin-film solid-electrolyte cells constructed of lithium based inorganic materials fabricated by multilayer sputtering. The ability of this fabrication technique to discretely layer or compositionally grade thin films provides a unique opportunity to investigate the effect of electrode-electrolyte interface structure on cell performance. Finally, the computer control associated with this fabrication technique will allow the deposition of multiple cells in a bipolar configuration with either series or parallel connection. It is anticipated that this research will directly lead to practical applications of thin film solid state batteries as integrated power sources for modern electronic circuits (i.e. microsensors, memory elements, displays, and timers). 


\section{Lawrence Livermore National Laboratory Livermore, CA 94550}

\section{Thermoelectric Quantum Wells}

Joseph C. Farmer

510/423-6574

Funding Profile

Date Started: January 15, 1994

FY 94 - $\$ 350,000$

Anticipated Duration: 3 Years

FY $95-\$ 350,000$

FY $96-\$ 350,000$

Solid state thermoelectric devices have no moving parts and can be used to convert heat directly into electricity. Such devices can also be used as chlorofluorocarbon (CFC)-free refrigerators, provided that an external voltage is applied. Unfortunately, thermoelectric devices are not as efficient as their mechanical counterparts. However, theoretical physicists at the Massachusetts Institute of Technology have recently used quantum mechanics to design a new class of thermoelectric materials that may improve the efficiency (figure of merit) of thermoelectric devices to a point where they are competitive with conventional internal combustion engines and CFC-based refrigerators. Process technology developed at Lawrence Livermore National Laboratory for the fabrication of $x$-ray optics is now being used to synthesize these new multilayer thermoelectric thin films. Multilayers are being made by alternately sputtering quantum well and barrier layers onto amoving substrate from dual magnetrons. A number of multilayer films, including high-temperature $\mathrm{Si}_{0.8} \mathrm{GeO}_{2} / \mathrm{Si}$ and low-temperature $\mathrm{Bi}_{0.9} \mathrm{Sb}_{0.1} / \mathrm{PbTe}_{0.8} \mathrm{Se}_{0.2}$, are being synthesized and evaluated. This research can lead to new materials and devices. 


\section{Lawrence Livermore National Laboratory Livermore, CA 94550}

\section{Porous Carbons: Controlling Structure, Composition and Performance}

Richard W. Pekala, Chemistry and Materials Science Department 510/422-0152

Funding Profile

Date Started: March 15, 1994

FY $94-\$ 335,000$

Anticipated Duration: 3 Years

FY $95-\$ 355,000$

FY $96-\$ 374,000$

This research examines the synthesis and processing conditions necessary to tailor the local structure and composition of porous carbons for potential applications in energy storage devices (i.e., batteries, capacitors). Carbon aerogels are being formed from resorcinol-formaldehyde and phenolic-furfural precursors. These porous carbons have low electrical resistivity, an ultrafine pore size distribution, high surface area (400 to 1100 square meters per gram, roughly the size of one or two basketball courts), and a solid matrix composed of interconnected particles or fibers. Preliminary data show that these materials are attractive electrodes for double. layer capacitors. Carbon foams derived from the phase separation of polyacrylonitrile/solvent mixtures are being investigated as lithium intercalation anodes for rechargeable lithium-ion batteries. These carbon foams differ from aerogels in that they have much larger pore sizes and one or two orders of magnitude lower surface area. High capacity and good cycleability are observed during lithium intercalation experiments. These materials can potentially lead to new batteries with energy densities that are approximately four times greater than conventional nickelcadmium batteries. In summary, this research project investigates sol-gel polymerization of multifunctional organic monomers, the phase separation of polymer/solvent mixtures, the formation of porous composites, intrinsic chemical doping, and pyrolysis in controlled atmospheres. A variety of characterization tools are being used to study the structure and properties of porous carbons. The overall objective is to develop a fundamental understanding of how morphology, chemical composition, and local order affect the electrochemical performance of porous carbons. The potential payoff from this research is the development of new energy storage devices with superior performance. 


\section{Los Alamos National Laboratory \\ Los Alamos, NM 87546}

\section{Synthesis and Propertles of High Strength Nanolayered Composites}

Michael Nastasi

505/667-7007

Funding Profile

Date Started: February 15, 1993

FY $93-\$ 150,000$

Anticipated Duration: 3 Years

FY $94-\$ 315,000$

FY $95-\$ 330,000$

The objective of this project is to synthesize and evaluate ultra high strength vapordeposited nanoscale materials both in the monolithic and composite form. Such materials have been shown to posses strengths that are within a factor of three or four of the theoretical shear strength $\approx \mu / 15$, where $\mu$ is the shear modulus. Synthesis of nanoscale materials presents the opportunity to develop a basic understanding of the deformation and fracture mechanisms that operate close to the theoretical limit of strength of materials to enable a new technological breakthrough, namely mechanical miniaturization. The availability of the fine-scale ultra high strength materials would provide the basis for fabricating, among others, miniature activators, springs, and diaphragms, for biomedical or sensor applications. The primary performance task will be to synthesize ductile materials with ultra high strength for application in mechanical miniaturization. 


\section{Los Alamos National Laboratory \\ Los Alamos, NM 87545}

\section{Experimental and Theoretical Studies of Inertial-Electrostatic Confinement}

Richard A. Nebel 505/667-7721

Funding Profile

Date Started: November 1, 1991 FY 92 - $\$ 400,000$ Anticipated Duration: 3 Years

FY $93-\$ 400,000$

FY $94-\$ 392,000$

A comprehensive study of inertial-electrostatic confinement (IEC) will be conducted. IEC is a plasma confinement scheme for fusion applications based on electrostatic fields. Unlike conventional magnetic confinement fusion, IEC devices produce fusion via nonMaxwellian beam-beam interactions; the kinetic energy of the beam ions being approximately the same as the potential on the grid. Experimental work complemented and guided by theoretical analysis will be pursued. The experimental effort will be centered at the University of Illinois. Experimental diagnostics will glean data to determine the spatial dependence of both the neutron-emission source and the associated electrostatic potential. These data will be used to assess and improve the understanding of IEC and to test new physics concepts that may enhance ion compression and collision rates in such devices. The computational strengths of Los Alamos National Laboratory (LANL) together with the phenomenological modeling capabilities of Energy/Matter Conversion Corp., (EMC2) will be used to achieve this mission. A three-dimensional semi-implicit Particle-In-Cell (PIC) code is currently being developed at LANL that is appropriate for modeling both the IEC experiments and conventional as well as newly developed phenomenological physics models of interest in their interpretation. Possible instabilities will be studied in order to determine their effect upon the electrostatic confinement. The primary goals will be to determine conditions for maximum ion confinement and to define appropriate experimental regimes for their test. 


\title{
Los Alamos National Laboratory \\ Los Alamos, NM 87646
}

\section{Pulsed Microwigglers for Innovative Free-Electron Lasers* \\ Roger W. Warren \\ 505/667-1988}

Funding Profile

Date Started: June 1, 1991

FY $91-\$ 300,000$

Anticipated Duration: 3 Years

FY $92-\$ 350,000$

FY $93-\$ 350,000$

\begin{abstract}
A pulsed microwiggler will generate a very strong wiggler field of short period. It will allow light of short wavelength to be generated by an free-electron laser (FEL) system that uses an unusually low energy accelerator that is, therefore, compact and inexpensive. This will lead to a new generation of FELs, revolutionizing the technology. The development will enable new applications for which FELs were previously considered too expensive and cumbersome. Development of such a wiggler will require extensive computer simulations, novel wiggler designs (both to generate fields of the required shape and magnitude and to allow heat to be extracted efficiently), advanced fabrication techniques (to achieve the required precision), state of the art power supplies (high, pulsed currents), and unusual test equipment (to measure fields inside the small wigglers). These developments can be divided into several stages that can be attacked sequentially. It is planned to design, build, and test such a microwiggler and use it in an existing FEL system at Los Alamos to generate UV light.
\end{abstract}

"Project Completed 


\section{Massachusetts Institute of Technology Cambridge, MA 02139}

\section{Superconducting Bitter Magnets \\ Leslie Bromberg, Plasma Fusion Center \\ 617/253-6919}

Date Started: May 1, 1993

Anticipated Duration: 3 Years
Funding Profile

FY $93-\$ 300,000$

FY $94-\$ 300,000$

FY $95-\$ 300,000$

A novel process for manufacturing high temperature superconducting magnets using thick-film superconducting material on structural plates is described. This technique is similar to that used in constructing Bitter magnets. The superconductor is manufactured in the required shape, avoiding the need to develop ductile wires. The structural metal plate serves as the material as well as the quench protector. A dielectric with high electrical resistivity is placed between the conductor and the metal plate (copper, aluminum, composite materials). This method can be utilized for manufacturing solenoidal, toroidal, saddle, and other types of magnets with both high- $T_{c}$ and low- $T_{0}$ superconductors. This project will address issues faced in this type of magnet construction (quench protection, materials compatibility, stability, and cooling). A theoretical program to gain understanding on these issues will be carried out. Experiments will be conducted to determine the feasibility of manufacturing magnets using this technique. Several methods for manufacturing the superconductor will be tested. Interaction with the manufacturers to improve the performance of superconducting materials for this application will be maintained. It is expected that in the final phase of this program, magnets will be constructed and tested. A team arrangement between the Plasma Fusion Center at the Massachusetts Institute of Technology (MIT) and the Superconductivity Technology Center at the Los Alamos National Laboratory (LANL) has been established. 


\section{University of Michigan \\ Ann Arbor, MI 48109}

\section{Development and Applications of the Positron Microscope*}

David W. Gidley, Department of Physics

313/936-1134

Funding Profile

Date Started: January 15, 1990

FY $90-\$ 173,000$

Anticipated Duration: 4 Years $^{\star \star}$

FY $91-\$ 175,000$

FY $92-\$ 175,000$

The operation of the first positron microscopes in 1988 demonstrated a totally new contrast mechanism for microscopic imaging. Specifically, the positron reemission microscope images anti-matter positrons that have been implanted into a sample and subsequently reemitted from its surface. Image contrast, determined by the sample's positron reemission probability, depends on the unique behavior of positrons in solids. The goal of this research is to move this new technology beyond the current demonstration phase $(3,000-10,000 \AA$ resolution) by constructing and operating a $100 \AA$ resolution instrument. This device would allow the assessment of the technique's ultimate capabilities, as well as allow investigation of several outstanding problems which the proposed microscope should make a unique contribution to solving. These problems include: (a) analysis of sub-25 $\AA$ films by positron tunneling microscopy; (b) unique applications in surface catalysis including, for example, analysis of systems with high $Z$ substrates where electron microscopic techniques fail; (c) analysis of operation and failure modes of microelectronic devices; and (d) imaging of selected biological systems, such as lipids and proteins in cell membranes. A program complementary to this has been initiated at the Idaho National Engineering Laboratory to construct a positron beam with a minimum intensity of $10^{10}$ positrons/sec. A beam of such intensity would be required for several applications including use in a sub-10 $\AA$ resolution microscope that would be constructed if, based on the results of this project, it is judged to be feasible and useful.

\footnotetext{
*Project Completed

**Includes 12 month no-cost extension
} 


\section{University of Michigan \\ Ann Arbor, MI 48109}

\section{Feasibility of a Novel Approach for Fast, Economical Determination of Radiation Damage in Nuclear Reactor Cores}

Gary S. Was, Department of Nuclear Engineering 313/763-4675

Funding Profile

Date Started: November 1, 1992

FY $93-\$ 156,000$

Anticipated Duration: 3 Years

FY $94-\$ 145,000$

FY $95-\$ 149,000$

The objective of this project is to determine the feasibility of using proton irradiation as a radiation damage tool, resulting in order-of-magnitude savings in time and cost over current methods to study radiation damage. The feasibility will be established through the application of proton irradiation to the determination of the mechanism of irradiation assisted stress corrosion cracking (IASCC) in light water reactors (LWRs). The technique is ideally suited to this major industry problem. The emphasis of the technical program will be on the role of grain boundary chemistry and microstructural changes on IASCC. High energy proton irradiation has recently been shown to produce grain boundary segregation of the major alloying elements and impurities, and a microstructure that is comparable to that produced by neutron irradiation in a fraction of the time and at a fraction of the cost. This program is designed to uncover the effects of grain boundary impurity segregation, chromium depletion, and the irradiated microstructure on IASCC. It involves both experimental and computational efforts that have been developed in our laboratory. The plan also calls for investigation of the dose, dose rate, temperature and injected hydrogen effects and comparison with available neutron irradiation data. The combination of microstructure characterization with its dependence on critical irradiation param.eters will provide both a better understanding of the role of irradiation in the mechanism, as well as an assessment of the feasibility of using proton irradiation to study neutron irradiation in LWR cores. Collaborations with industry and national laboratories have been established to exchange materials that will allow us to benchmark results of proton irradiation against neutron irradiation and to determine the irradiation conditions that produce the best match. Because the time and cost involved in these experiments is a small fraction of that required for neutron irradiation, the technique will provide a more cost-effective and time-efficient method of studying radiation change in core structures and in assessing new materials. 


\section{University of Missouri \\ Columbia, MO 65211}

\section{A Study of Potential High Band-Gap Photovoltaic Materials for a Two Step Photon Intermediate Technique in Fission Energy Conversion*}

Mark A. Prelas, Nuclear Engineering Program 314/882-3550

Funding Profile

Date Started: December 1, 1990

FY $91-\$ 305,000$

Anticipated Duration: 3 Years

FY $92-\$ 294,000$

FY $93-\$ 317,000$

The efficiency of modern-day power plants is limited by the steam cycle that they employ. Future power plants may be able to improve upon the efficiency of the steam cycle, provided that other energy conversion techniques become available. One such energy conversion method is excimer channeling. Excimer channeling is a method of efficiently creating a narrow band photon spectrum directly from the products of nuclear reactions. This narrow band photon spectrum can be used in an energy conversion cycle based upon photovoltaic reactions. This project addresses the issue of photovoltaic materials that can interface with the narrow band photon spectrum in the excimer channeling energy conversion method. Photovoltaics are generally thought to be inefficient because of their association with solar cells. Solar cells are photovoltaic cells that convert the broad band photon spectrum of the sun directly into electricity at an efficiency of $10 \%$ to as much as $20 \%$. Conversion of photons into electricity could be very efficient (as high as $85 \%$ ) if the photon spectrum were sufficiently narrow, such as that produced by excimer channeling, and matched to the bandgap of the photovoltaic material. Development of high bandgap photovoltaic materials that match the excimer channeling photon spectrum is the goal of this research program. This effort centers on materials with bandgaps exceeding $5 \mathrm{eV}$. High bandgap crystals will be synthesized, doped to form p-n junctions, characterized by various surface analysis methods, made into photovoltaic cells, the cells' characteristics tested, and the cells' tolerance to various types of electromagnetic radiation assessed.

*Project Completed 


\section{National Renewable Energy Laboratory 1617 Cole Boulevard Golden, CO 80401-3393}

\section{PV-Powered, Electrochromic Windows}

David K. Benson, Basic Sciences Division 303/384-6462

Funding Profile

Date Started: February 15, 1994

FY 94 - \$330,000

Anticipated Duration: 3 Years

FY $95-\$ 330,000$

FY $96-\$ 330,000$

This project will develop a retrofit window treatment for architectural windows. The window treatment will be a combination of thin-film photovoltaic cells and an electrochromic coating, both deposited onto a flexible polymer film. The coated polymer film will be applied to the interior surfaces of existing building windows and used to modulate the solar transmittance into the building thereby providing automatic solar-gain control and daylighting control functions which will reduce heating, cooling, and lighting energy usage in the building. The self-powered window obviates the need for costly electrical wiring. This kind of "smart" window covering has the potential to balance the performance of the window, giving it a net energy benefit. It has been predicted to be able to reduce the cooling power demand of a south-facing window in a climate such as southern California by about $40 \%$ and to have similar benefits in other locations. A large fraction of the billion square meters of existing building windows in the U.S. could benefit from this kind of treatment. At present, an estimated 1 to $1.5 \%$ of the total cooling energy need in buildings and 10 to $30 \%$ of the peak electric utility power demand is caused by windows amounting to about a $1500 \mathrm{MW}$ increase in electric utility peak electric power demand each year due to new windows at a national operating cost of about $\$ 10$ billion. New photovoltaic and electrochromic coating designs and new processes for their deposition onto flexible polymer substrates will be developed in this project. 


\section{National Renewable Energy Laboratory 1617 Cole Boulevard Golden, CO 80401-3393}

\section{Hot Carrler Solar Cells}

Mark C. Hanna, Basic Sciences Division 303/384-6620

Funding Profile

Date Started: February 15, 1994

FY $94-\$ 330,000$

Anticipated Duration: 3 Years

FY $05-\$ 330,000$

FY $96-\$ 330,000$

This project is focused on the development and understanding of a new kind of high efficiency solar cell, called a Hot Carrier Solar Cell (HCSC), which may have the potential to double the maximum efficiency of conventional solar cells. The ultimate thermodynamic conversion efficiency of an optimized HCSC is $66 \%$, compared to $31 \%$ for an optimized conventional single bandgap solar cell. This project explores a new approach for increasing the efficiency of solar cells by attempting to utilize the excess kinetic energy of higher energy (hot) carriers generated by the absorption of high energy photons in the solar spectrum. Normally, the excess kinetic energy of hot carriers created by absorption of solar photons in photovoltaic cells is converted to heat and is thus unavailable for useful work. The HCSC employs a new type of semiconductor structure (called a superlattice) to absorb the solar photons and to inhibit hot carriers from cooling in the photovoltaic device. Bandgap engineering techniques will be used to control important physical properties of the superlattice, such as the hot carrier energy loss rate, hot carrier mobility, and the absorption threshold. Hot carriers from the superlattice region are collected in high bandgap contacts to produce a higher photovoltage. With this combination, the photocurrent and photovoltage of the cell can be separately controlled and optimized, unlike the conventional p-n photovoltaic cell where the photocurrent and pirotovoltage are coupled. The HCSC is fabricated from Group III-V semiconductor compounds and alloys grown by low pressure organometallic chemical vapor deposition. This project will synthesize HCSCs, measure their performance and properties, compare them to appropriate conventional solar cells, and develop a theoretical model for predicting the device characteristics of the HCSC. 


\section{National Renewable Energy Laboratory 1617 Cole Boulevard Golden, CO 80401-3393}

\section{Atomic and Nanoscale Engineering of Thermophotovoltaic Semiconductors Using Scanning Probe Microscopy Techniques}

Lawrence L. Kazmerski, Photovoltaics and Basic Sciences Division 303/275-3711

Funding Profile

Date Started: July 10, 1994

FY $94-\$ 177,000$

Anticipated Duration: 3 Years

FY $95-\$ 552,000$

FY $96-\$ 340,000$

This project uses scanning probe microscopies for the atomic-scale engineering of semiconductors leading to advances in understanding their improvement, and their use in energy-conversion thermophotovoltaic (TPV) structures and devices-cells designed to produce electricity from surfaces emitting radiation in the 1400 to $2000 \mathrm{~K}$ range. This program consists of three interrelated segments: (1) preparation of selected GalnAs and GainAsP alloy surfaces having suitable compositions; (2) use of modern electronic structure theory to predict the properties of these semiconductor surfaces before and after atomic-scale engineering takes place and to provide guidance for the experiments; and, the central and primary activity, (3) evolution of the novel atomic processing microscope to image, process (including atom removal and placement), and characterize these semiconductors with the same nanoscale spatial resolutions and to produce nanometerscale optimized TPV structures for the next generation of these energy conversion devices. These atomic-scale investigations involve the manipulation of atoms in order to study the fundamental defect properties that limit both materials properties and device performance. The program provides the first atomic engineering directed toward these III-V materials. It further provides fundamental information of the nature of defects, their electrooptical properties and the ability to electronically heal them with intrinsic and extrinsic atomic species. This project links events on the atomic scale to the current understanding of semiconductor surface and interface physics. The project provides firsttime characterization of the electro-optical properties of TPV semiconductors in compositional ranges not previously investigated. This information is used to demonstrate optimized next-generation TPV structures that will lead to highly efficient cells for energy applications. 


\section{Northeastern University}

\section{Boston, MA 02115}

39. Further Development of the Pneumatic Method to Harness Low-Head Hydropower and of Its Experimental Implementation In the State of Maine*

Alexander M. Gorlov

617/437-3825

Date Started: December 15, 1990

Funding Profile

Anticipated Duration: 3 years ${ }^{\star *}$

FY $91-\$ 94,000$

FY $92-\$ 81,000$

The objective of the project is a further theoretical study of the pneumatic method to harness low and ultra low head hydropower and to demonstrate that such an approach can be economically and environmentally efficient for riverine power installation. The concept was originally offered in 1978-1980 for harnessing tidal power. The principal idea of the method is to utilize air turbines instead of conventional hydroturbines by means of converting energy of the flowing water into energy of compressed air. A pneumatic hydropower plant would cause minimal environmental distortion in the river and require substantially less land taking for a water pool than a conventional hydroturbine installation. There are two primary aspects of the research project: (a) to complete an analysis of air chamber parameters, mechanical and energy losses, air turbine operation; and (b) to perform a feasibility study of a pneumatic power installation for a selected riverine site in the state of Maine.

*Project Completed

**Includes 12 month no-cost extension 


\section{Oak Ridge National Laboratory}

\section{P.O. Box 2008}

Oak RIdge, TN 37831

\section{Novel Composite Coatings for High Temperature Friction and Wear Control}

Theodore M. Besmann, Metals and Ceramics Division 615/574-6852

Funding Profile

Date Started: November 1, 1991

FY $92-\$ 428,000$

Anticipated Duration: 3 Years

FY $93-\$ 250,000$

FY $94-\$ 260,000$

The development of improved, self-lubricating materials is critical for enabling progress in many industrial sectors: transportation, industrial machinery, business machines, aerospace, and defense. Its impact on the economy will therefore be large and diverse, spanning devices from high-temperature turbine engines to moving parts in heat-treatment systems for integrated circuitry. Chemical vapor deposition (CVD) techniques offer the opportunity to create very uniform self-lubricating composites which slowly wear away to expose pockets of lubricants which then spread across the surface. In CVD, gaseous reactants are allowed to flow over a heated substrate where they react and deposit a solid coating. Solid lubricants have higher use temperatures and higher load-bearing capacities than do liquid lubricants. Consequently, they find use in applications where liquid lubricants prove inadequate. It has been noted that because buckminsterfullerene $\left(C_{60}\right)$, is a spherical macromolecule and is thought to be very stable and slow to react with other substances, it should make an excellent lubricant. This project utilizes the controlled wear of a hard matrix to reveal the embedded high-temperature, solid lubricant. Such a composite coating would be produced by CVD, which has been demonstrated capable of producing multiphase coatings of controlled composition and microstructure. The $\mathrm{C}_{60}$ phase cannot be simultaneously formed during deposition, as can other of the proposed lubricants. The material can be incorporated into a coating, however, by entrainment in the coating gases. 


\section{Oak Ridge National Laboratory \\ P.O. Box 2008 \\ Oak RIdge, TN 37831}

\section{Synthesis of Advanced Composite Ceramic Precursor Powders by the Electric Dispersion Reactor}

Michael T. Harris, Chemical Technology Division

615/574-1275

Funding Profile

Date Started: July 1, 1991

FY $91-\$ 201,000$

Anticipated Duration: 3 Years

FY 92 - $\$ 179,000$

FY $93-\$ 365,000$

FY $94-\$ 325,000$

The use of high-intensity-pulsed electric fields for droplet size control in dispersed liquid systems is being investigated. This technology has been utilized in a device called the electric dispersion reactor (EDR) to carry out the synthesis of micron-sized particles for the production of precursor powders of advanced ceramic materials. In this approach, pulsed electric fields are employed to create dispersions of microscopic conducting (aqueous-based) drops in nonconducting (organic) liquids. Each of these droplets becomes a localized microreactor where reactants in the organic phase diffuse into the aqueous droplets in which precipitation and gelation occur, while water and reaction products diffuse into the organic phase. The particle morphology is altered by varying reactant compositions in the liquid-liquid system while achieving intraparticle stoichiometric consistency. This leads to the production of high-quality precursor powders that, in turn, yield dense, consistent green-body material. Furthermore, this method requires far less energy expenditures than conventional approaches that rely on such inefficient operations as solids blending, mixing, and grinding to accomplish the formation of mixed-oxide precursor material.

*Project Completed 


\section{Oak Ridge National Laboratory \\ P.0. Box 2008 \\ Oak RIdge, TN 37831}

\section{Blocatalytic Design by Chemical Modification*}

Jonathan Woodward, Chemical Technology Division

615/574-6826

Funding Profile

Date Started: October 1, 1991

FY 92 - $\$ 285,000$

Anticipated Duration: 3 Years

FY $93-\$ 260,000$

FY 94 - $\$ 235,000$

The overall goal of this project is to demonstrate that the generation of a biocatalyst with multiple active sites is possible by the chemical modification of a single enzyme and, once formed, it will have utility in the generation of energy and the degradation of polymeric and monomeric compounds. The model enzyme chosen to study is cellobiohydrolase I (CBH I), the major component of the cellulase enzyme mixture produced by the fungus, Trichoderma reesei. This enzyme catalyzes the hydrolysis of cellulose to cellobiose and can be purified relatively easily and quickly in preparative quantities. If, besides being an hydrolase, oxidase activity could be conferred upon $\mathrm{CBH} \mathrm{I}$, then it is conceivable that naturally occurring cellulosic substrates (lignocellulose) could be biodegraded (requiring both oxidation and hydrolysis) by a single biocatalyst by abolishing or reducing the pretreatment requirement. Consequently, there would exist a good possibility for a dramatic reduction in the costs and energy requirements associated with the enzymatic degradation of cellulose that could contribute to an energy-efficient and cost-effective waste management and bioprocessing system. The reason for this is that current pretreatment methods are costly and energy intensive, requiring capital investment as well as routine operational costs. Objectives of the research include: (a) the purification of gram quantities of $\mathrm{CBH} \mathrm{I}$; (b) the attachment of redox-active inorganic groups to the polypeptide of $\mathrm{CBH} \mathrm{I;} \mathrm{(c)} \mathrm{a} \mathrm{comparison} \mathrm{of} \mathrm{the} \mathrm{kinetic} \mathrm{properties} \mathrm{of} \mathrm{native}$ and modified $\mathrm{CBH} \mathrm{I}$, including the determination of their substrate specificity; (d) the demonstration of the efficient biodegradation of various lignocellulosic biomass sources by the modified enzyme; and (e) a comparative economic analysis of an enzymatic hydrolysis of lignocellulose to glucose process employing conventional pretreatment techniques or chemically modified biocatalysts.

*Project Completed 


\section{Princeton University \\ Princeton, NJ 08544-1009}

\section{Optimally Controlled Interior Manipulation of Sollds}

Herschel Rabitz, Department of Chemistry

609/258-3917

Funding Profile

Date Started: November 19, 1992

FY $93-\$ 329,000$

Anticipated Duration: 3 Years

FY $94-\$ 349,000$

FY $95-\$ 299,000$

In the processing of solid state materials, manipulation or modification is usually confined to their accessible exterior surfaces. This project is concerned with the development of a technique for modification of the interior solids without the necessity of opening up the material. The technique is based on the concept of designing and creating temporally and spatially tailored laser pulses that deposit energy on the surface for the purpose of launching an intense acoustic wave that focuses within the solid. Taking account of the relatively large illumination area on the surface and the focusing nature of the acoustic waves, it should be possible to minimally disrupt the surface while still attaining significant degrees of interior modification at the target volume. A central feature of this new materials processing method is its reliance on destructive and constructive interference between the ensuing shear and compressional acoustic waves. The delicacy of this method calls for the use of optimal design and control techniques for the temporal and spatial shaping of the laser beams. The research will consist of a theoretical design effort that closely interacts with a laboratory program for implementation of the design concepts. The research will be conducted in a series of steps, starting with low intensity focusing and proceeding to the regime where permanent solid interior alteration is possible. In accord with this sequential development, theoretical design work will move from the linear to the nonlinear regimes of solid mechanics and the laboratory studies will involve increasing laser pulse intensities and complexities of pulse shapes. The overall purpose of the research is to establish the feasibility of achieving interior manipulation of solids. Particular attention will be paid to discerning the flexibility as well as limitations of the physical process. An established capability for interior manipulation of solids would open up many opportunities including interior annealing, induced phase transitions, induced chemical reactions, crack arresting, controlled defect site generation, and interior welding. 
Purdue University

1296 Potter Engineering Center

West Lafayette, IN 47907

\section{Zeollte Catalysis in Conversion of Cellulosics}

George T. Tsao, Laboratory of Renewable Resources Engineering 317/494-7024

Funding Profile

Date Started: February 15, 1992

FY $92-\$ 255,000$

Anticipated Duration: 3 Years

FY $93-\$ 235,000$

FY $94-\$ 244,000$

The use of zeolite catalysts may improve conversion of cellulosics in two important ways, namely (a) reduction of glucose inhibition of cellulase activities; and (b) efficient conversion of xylose into xylulose and then ethanol. This project will study adsorption of carbohydrates, hydrolysis of oligosaccharides, and aldose-ketose isomerization catalyzed by zeolites under various conditions. High pressure liquid chromatography, nuclear magnetic resonance and infrared measurements will be used to detect sugars and to examine their interactions with. the zeolites. .These studies will help to elucidate the mechanism, kinetics, diffusion, and equilibrium of the reactions as they are affected by the presence of zeolites. Zeolite-promoted reactions including isomerization and oligomer hydrolysis can be coupled with biological reactions including enzymatic hydrolysis and yeast fermentation for the above-mentioned improved overall conversion of cellulosics. 


\section{Rensselaer Polytechnic Institute}

Troy, NY 12180-3690

\section{Cationically Polymerizable Monomers Derlved From Renewable Sources*}

James V. Crivello, Department of Chemistry 518/276-6825

Funding Profile

Date Started: February 1, 1991

FY $91-\$ 310,000$

Anticipated Duration: 3 Years**

FY 92 - $\$ 235,000$

FY $93-\$ 248,000$

The objective of this project is to make use of a wide range of products obtained from plant sources as monomers for the direct production of polymers that can be used for a wide range of plastic applications. In particular, high-volume American agricultural products such as soybean, cotton or linseed oils or forestry products such as lignin and cellulose are targeted for use either directly or with very slight modification for the production of the plastics. The monomers thus obtained will be rapidly and efficiently converted to polymers using ultraviolet light or heat employing unique catalysts developed in this laboratory. It is expected that these catalysts provide a low energy and pollutionfree means for the direct fabrication of the plastics. Furthermore, the polymers that are formed are expected to be prone to biodegradation and to pose little long term accumulation or pollution hazard.

"Project Completed

*\#Includes 6 month no-cost extension 


\section{Sclence Research Laboratory}

1160 Ballena Boulevard, Sulte 100

Alameda, CA 94601

\section{The Plasma Centrifuge (A Compact, Low Cost, Stable Isotope Separator)* \\ Philip Greene \\ 617/547-1122}

Funding Profile

Date Started: September 15, 1991

FY 91 - $\$ 495,000$

Anticipated Duration: 42 Months*

FY $92-\$ 441,000$

FY $93-\$ 317,000$

The objective of this project is to make practical a new type of isotope separator called the Plasma Centrifuge. The Plasma Centrifuge is based on the concept of a cylinder of ionized matter (plasma) contained by a magnetic field and set into rotation by application of an electromagnetic body force. The typical embodiment consists of a rotating column that is fed by a vacuum arc plasma source at one end. As the plasma streams towards the other end of the chamber, centrifugal forces cause the heavier isotopes of the plasma ions to move nearer the periphery of the rotating column, resulting in partial separation between the constituent isotopes. Collectors placed at the other end of the column can collect either the outer portion that is enriched in the heavier isotope, or the inner portion that is enriched in the lighter isotope, as desired. This Plasma Centrifuge apparatus fits into a small room and can enrich dozens of isotopes with a throughput of about 1-3 grams/hour of enriched product. Such a capability would make this centrifuge a useful new separator to supply the U.S. demand for a varieity of enriched isotopes that are badly needed in these quantities in the fields of basic research in physics/chemistry/ geology/medicine and in medical diagnostics radiological practice. The cost, modularity and size of this approach makes the Plasma Centrifuge a potential replacement for CALUTRONS, which are today's primary source of supply of enriched isotopes.

*Includes 6 month no-cost extension 


\section{Stanford University \\ Stanford, CA 94306}

\section{Nonlinear Optics in Doped Fibers \\ Richard H. Pantell, Electrical Engineering Department 415/723-2564}

Funding Profile

Date Started: May 1, 1992

FY 92 - $\$ 364,000$

Anticipated Duration: 3 years

FY $93-\$ 363,000$

FY $94-\$ 366,000$

The objective of this project is to develop a novel and simple technology for optical, allfiber switches based on the third order nonlinear effect in doped, single-mode fibers. The principle behind these devices is that, when exciting a transition near resonance, the electronic distribution changes and so does the contribution of this transition to the refractive index of the material. This effect exists in pure silica, but it is extremely weak, and in undoped, pure silica fibers. Tens of watts and tens of meters of fiber are required to induce the phase shift of $\pi$ needed for switching. The novelty of this approach is to use a fiber doped with an appropriate impurity and excite it optically near an absorption resonance of this impurity to produce strongly enhanced nonlinear susceptibilities. Modeling shows that it is then possible to reduce the pump and length requirements by several orders of magnitude each, and to produce a $\pi$ phase shift in centimeter lengths with milliwatts of pump power. The ultimate thrust of this project is to investigate this effect with a variety of impurities exhibiting high oscillator strength transitions to produce both high speed and very short devices. For picosecond response times, the reduction in the pump power-fiber length product is predicted to be $7-8$ orders of magnitude over undoped silica. Slower but useful devices will also be investigated using well-understood erbium and neodymium-doped fibers that have been extensively studied as lasers and amplifiers but not as nonlinear switches. This investigation is anticipated to open the door to the first low-power, ultra-short switches and modulators made with single-mode optical fibers, operated with a low-power, long-lifetime laser diode. Such components are not currently available in a form compatible with fiber optic systems, either from fiber-based or integrated-optic based elements. There are a variety of energy applications for the proposed research, including oil exploration, control of power substations, and management of consumer distribution systems. Interactions with several companies are planned throughout this study for directivity, technology transfer, and manufacturing of some of the devices tested under the program. 


\section{Texas A\&M University \\ College Station, TX $\mathbf{7 7 8 4 3}$}

\section{Utilizing Laser Spectroscopy of Noble Gas Tracers for Mapping Oll and Gas Deposits}

Hans A. Schuessler, Physics Department

409/845-5455

Funding Profile

Date Started: December 15, 1992

FY 93 - $\$ 152,000$

Anticipated Duration: 3 Years

FY $94-\$ 164,000$

FY $95-\$ 168,000$

Radioactive nobel gases are being used as tracers to measure the structure of gas and oil deposits. Due to their chemical inertness, they offer the advantage that they do not react with the environment with which they are in contact. Usually, a nobel gas tracer is injected at an injection well and gas or liquid samples are taken from a production well. When a long-lived tracer, such as ${ }^{35} \mathrm{Kr}\left(\mathrm{T}_{1 / 2}=10.8 \mathrm{y}\right)$, is used for extended deposits, the specific activities of the production well samples are low. The measurements are then difficult, since the sample must be analyzed in an ultralow counting facility to minimize the background counts. This problem exists even when large amounts of tracer gas with high radioactivity levels (several hundred curie) are injected for which extensive safeguarding of the personnel is necessary. The objective of this project is to improve the sensitivity of nobel gas detection in samples taken from production wells by more than three orders of magnitude by applying optical rather than nuclear detection. The novel technique will not only reduce the required radioactivity levels at the injection site, but work even with stable tracer isotopes thus abolishing most handling, transportation and storage problems. Collinear fast beam laser spectroscopy will be used for which a sensitivity at the few atoms ievel and also complete isotopic selectivity has already been demonstrated. The construction of a prototype analytical instrument is planned, that can routinely and quickly analyze samples for their noble gas content. Single nobel gas atoms can then be detected, even in the presence of other isotopes and atoms which are more abundant by a factor of about $10^{15}$. Since sample enrichment might not be necessary and stable noble gas tracers are inexpensive, the method promises to be more cost effective and environmentally safe than present nuclear decay detection. 


\title{
The University of Texas at Austin
}

\author{
Austin, TX 78712
}

\section{Synthesis of New High Performance Lubricants and Solid Lubricants*}

Richard J. Lagow, Department of Chemistry $512 / 471-1032$

Funding Profile

Date Started: June 1, 1991

FY $91-\$ 377,000$

Anticipated Duration: 3 Years

FY $92-\$ 272,000$

FY $93-\$ 218,000$

Work will be conducted on the synthesis and characterization of perfluoropolyethers, an extraordinary class of high performance lubricants, by a relatively new technique, direct fluorination, that is emerging as the best way to prepare perfluoropolyethers. Many new and important classes of perfluoropolyethers will be prepared with very significant potential as lubricants. Currently, the highest obtainable molecular weight perfluoropolyether synthesized using conventional polymerization processes is 50,000 . This fluid with a molecular weight of 50,000 has a viscous syrup-like consistency. High molecular weight solids with a perfluoropolyether backbone have not been attained using methods other than direct fluorination technology. There exists now the capability to synthesize perfluoropolyethers with molecular weights over 1,000,000. Thus, solid perfluoropolyether lubricants are accessible for the first time. A feature of direct fluorination technology where hydrocarbon structures are converted to fluorocarbon structures is that the organic precursors are converted to fluorocarbon fluids and solids without substantial cross-linking and without increased or decreases in degree of polymerization. The synthesis of hydrocarbon polymers as starting materials has many other advantages and introduces great flexibility and capabilities not attainable using polymerization processes with various perfluorinated ethylene oxides. Work will be done on many generic classes of solid fluorocarbon lubricants. The capability to make perfluoropolyethers soluble (miscible) with less expensive hydrocarbon lubricants and poly alpha olefins has recently been developed. One of the most important and promising prospects of this research is the synthesis of chlorinated perfluoropolyether fluids that are very compatible and soluble in hydrocarbons offering potential as high performance lubrication additives.

*Project Completed 


\section{The University of Texas at Austin}

\section{Austin, TX 78712-1063}

\section{The Rallplug: Development of a New Ignitor For Internal Combustion Engines*}

Ronald D. Matthews, Department of Mechanical Engineering 512/471-3108

Funding Profile

Date Started: January 15, 1991

FY $91-\$ 500,000$

Anticipated Duration: 43.5 Months**

FY $92-\$ 500,000$

FY $93-\$ 500,000$

Although conventional spark plugs appear to be entirely suitable for spark ignition (SI) engines, the design of the $\mathrm{SI}$ engine is limited by the characteristics of the ignitors. That is, if superior ignitors were available, the $\mathrm{Sl}$ engine could be designed in a manner that would yield reduced emissions and improved fuel economy. Similarly, the design of virtually all types of internal combustion engines is limited in one way or another by the characteristics of the available ignitors. In this project, a new type of ignitor is being investigated that operates on a much different principle than either conventional ignitors or any of the other advanced ignitor concepts that have been studied recently. Technology is being transferred from "star wars" to the automotive industry--railguns (a kinetic energy defense weapon) are being miniaturized to generate a new ignitor for internal combustion engines. Two characteristics make the miniaturized railgun, or "railplug", highly attractive as a replacement for conventional ignitors: a relatively large mass of plasma is generated and the plasma leaving the muzzle of the railplug has a high velocity. The advantages of using a railplug ignition system in three different engine applications are being investigated: replacement of spark plugs in both conventional SI engines and in dilute homogeneous charge SI engines; and replacement of glow plugs in indirect injection diesels to improve cold start characteristics. The primary objectives of the research are to improve internal combustion engine performance and fuel economy and to reduce emissions.

*Project Completed

**Includes 7.5 month no-cost extension 


\section{University of Washington \\ Seattle, WA 98196}

\section{The Supersonlc-Mixing, Shock-Wave Reactor: An Innovative Approach for Efficient Chemical Production}

Arthur T. Mattich, Aerospace and Energetics Research Program 206/543-6181

Funding Profile

Date Started: June 15, 1993

FY $93-\$ 272,000$

Anticipated Duration: 3 Years

FY $94-\$ 418,000$

FY $95-\$ 309,000$

The production of many commercially-important chemicals involves pyrolysis of hydrocarbon feedstocks, an energy-intensive process that is now carried out by heating components of oil or natural gas in a furnace. This research will examine the potential of a novel approach for pyrolysis, the supersonic-mixing, shock-wave reactor, for reducing the energy consumption and production cost of ethylene and other compounds. These benefits arise from the use of gasdynamic processes to precisely control the temperature history of a reactant and thereby maximize the yields of valuable products. Initial studies indicate that ethylene yields in the pyrolysis of ethane may be $20-40 \%$ higher by using this method in place of conventional technology, and energy consumption may be reduced by $15 \%$ or more. The research program entails: 1) experimental investigation of fundamental aspects of supersonic mixing and reacting gas streams, such as mixing shear layers, shock structure and uniformity, and reaction pathways, that are important in the reactor's operation; 2) measurement of product yields under conditions of pyrolysis expected in commercial applications of the reactor; and 3) examination of methods of implementing the reactor for chemical manufacture. 


\section{Washington State University \\ Pullman, WA 99164-2814}

\section{Tunable Femtosecond UV Light Source Using a Novel Frequency Upshift Technique}

Henry C. Kapteyn, Department of Physics

509/335-4671

Date Started: April 19, 1993

Funding Profile

Anticipated Duration: 3 Years

FY $93-\$ 156,000$

FY $94-\$ 158,000$

FY $95-\$ 131,000$

The goal of this project is to implement a new approach for producing ultrashort light pulses at ultraviolet to extreme-ultraviolet wavelengths. An intense light pulse can be used to create a moving ionization front; light can be reflected from this front and experience a relativistic Doppler upshift. Two recently-developed technologies now make it possible to create tunable light pulses of unprecedented short duration using this technique. First, the recent development of small-scale terawatt femtosecond laser systems makes it possible to create an extremely abrupt moving ionization front, using the process of multiphoton ionization. Second, recently-developed techniques have resulted in the generation of single-optical-cycle duration pulses in the far-infrared. It is shown herein that it is possible to upshift such pulses to optical and shorter wavelengths while still retaining nearly single-cycle duration. This way, pulses of 1-5 femtoseconds duration in the UV to XUV region of the spectrum can be created. 


\section{Western Washington University \\ Vehicle Research Institute \\ Bellingham, WA 98225-9086}

\section{A Thermo-Photovoltaic Generator for Use In a Lightwelght Electric Car Michael R. Seal, Department of Technology Engineering 206-650-3045}

Funding Profile

Date Started: August 1, 1994

FY $94-\$ 145,991$

Anticipated Duration: 3 Years

FY $95-\$ 444,871$

FY $96-\$ 299,851$

In an internal combustion engine, fuel is mixed with air and periodically exploded. Because the explosions are of very short duration, the fuel combustion is incomplete, leading to carbon monoxide and hydrocarbon exhaust emissions. More pollution results because the temperature at the peak of the explosion is very high leading to the creation of nitrous oxides. A quiet, lightweight, clean, electric power source will be built in which a fuel is continuously burned in a ceramic tube, the tube glows red hot, and photovoltaic cells receive the infrared from this emitter and convert it to electric power. In effect, "solar" cells are used with a small manmade "sun" created by burning natural gas. Because fuel is burned continuously without periodic explosions, the thermophotovoltaic unit is very clean, quiet, efficient, and lightweight. The first benchtop experiments have already shown that this generator is 50 times cleaner than an internal combustion engine. Such a thermophotovoltaic unit has only recently become feasible as a result of new gallium antimonide cells fabricated by the JX Crystals Company. These new cells are much more sensitive in the infrared range than traditional solar cells. These new infrared cells will be integrated with an efficient natural gas fired infrared source with sufficient power to charge onboard vehicle batteries. The thermophotovoltaic eight cylinder unit alone, will be able to maintain an automobile at a speed of 60 miles per hour on level ground. Additional power for hill climbing and performance will be provided by onboard batteries. 


\section{SMALL BUSINESS INNOVATION RESEARCH PROGRAM}

The Small Business Innovation Research (SBIR) program was created in 1982 by Public Law 97-219 and reauthorized in 1992 until the year 2000 by Public Law 102-564. Program objectives are: to increase private sector commercialization of technology developed through Federal R\&D; to increase small business participation in Federal R\&D; and to improve the Federal Government's dissemination of information to women-owned-, and economically disadvantaged small business concerns.

Agencies with extramural R\&D budgets of over $\$ 100$ million are required to conduct an SBIR program using a set-aside of a stated percentage of that budget. The percentage increased from an initial $0.2 \%$ in 1983 to $1.25 \%$ in 1986 through 1992. Public Law 102564 increased the set-aside further, starting with $1.5 \%$ in 1993 and reaching a maximum of $2.5 \%$ in 1997 . The Department's SBIR budget for FY 1994 was about $\$ 53$ million.

In the Department of Energy, SBIR funds are used to support an annual competition for Phase I awards of up to $\$ 75,000$ for about 6 months to explore the feasibility of innovative concepts. Only Phase I winners are eligible to compete for Phase II awards, which are a continuation of the Phase I projects. Phase II is the principal research or R\&D phase. The maximum funding for Phase II projects through FY 1994 is $\$ 600,000$ over a two-year period. Technical topics for DOE's annual SBIR Solicitation are compiled by program managers in the agency.

In Fiscal Year 1994, the Division of Advanced Energy Projects (AEP) managed eight Phase II SBIR projects. Three of these projects were selected from grant applications submitted to the topic, "Novel Sources of Electromagnetic Radiation", in the 1991 DOE SBIR Program Solicitation; five of these projects were selected from grant applications submitted to the topic, "Design and Applications of Novel Materials", in the 1993 DOE SBIR Program Solicitation. AEP is managing eleven Phase I SBIR projects: four of these were awarded under the topic, "Green Car: Scientific Approaches to Automotive Applications (subtopic - Novel Approaches to Propelling Automobiles)" and seven were awarded under the topic, "Design and Applications of Novel Materials". These latter two topics were included in the 1994 DOE SBIR Program Solicitation. 


\title{
PHASE I SBIR PROJECTS
}

\author{
Advanced Modular Power Systems, Inc. \\ 4667 Freedom Drive \\ Ann Arbor, MI 48108
}

\section{A Low Emission Alkall Metal Thermal to Electric Converter Automotive Power System}

Thomas K. Hunt $313 / 677-4260$

Funding Profile

Date Started: August 15, 1994 FY $94-\$ 74,558$

The Alkali Metal Thermal to Electric Converter (AMTEC) is a static energy conversion device that operates at thermal to electric conversion efficiencies that are independent of size, have reached $19 \%$, and are expected to reach $25 \%$ to $30 \%$ in early 1995 . These systems operate silently, with no moving parts and can utilize any source capable of delivering heat at $700^{\circ} \mathrm{C}$ to $900^{\circ} \mathrm{C}$. Because they are as efficient as small internal combustion engines over a wide range of output (within $5 \%$ of peak efficiency from $15 \%$ to $85 \%$ of full power), but use external combustion, they are expected to have the lowest emissions possible for a given electrical output. Their output is $D C$, and, with appropriate series connection of modules, AMTEC can deliver voltages to match those provided by the battery systems of electric vehicles either for charging or for direct operation of electric motor drives. While AMTEC systems have been under development for years, recent developments made in programs directed toward spacecraft power systems have led to much simpler cell designs, far higher reliability, greatly improved modeling methods, and a clear path to modules appropriate for the assembly of multi-kilowatt systems. This project will demonstrate the feasibility of this approach through design, analysis, and the fabrication and testing of subscale modules. In Phase I, a system design will be developed and used to guide a series of experiments whose results will allow a clear test of the feasibility of the AMTEC approach. Phases II and III will demonstrate full scale module performance and show that they can be assembled into units appropriate for use in a hybrid-electric vehicle. The experimental work in Phase I will develop the first multitube vapor-vapor AMTEC module and use its performance to refine the state-of-the-art analytical models for AMTEC. The models will then be used to determine the feasibility of a full-scale system and direct the statement of work for Phase II. The Phase II program will have input from the automotive industry. 


\title{
EIC Laboratories, Inc.
}

111 Downey Street

Norwood, MA 02062

\section{Economical Photochromic Films for Solar Thermal Control}

\author{
R. David Rauh \\ 617/769-9450
}

Date Started: August 15, 1994

Funding Profile

FY $94-\$ 75,000$

The goal of this work is to develop a robust, thin-film coating, less than $1 \mu \mathrm{m}$ thick, that can be applied to surfaces, rendering them photochromic in sunlight with respect to both the visible and near infrared components of the solar spectrum. Applied to windows, these single layer "chromogenic" coatings are projected by modeling studies to result in large energy savings by solar management, particularly in buildings dominated by their cooling load. The planned thin-film approach would differ from current photochromic technologies, which are generally silver-based. Current technologies are not easily adapted to architectural glass and require bulk glass or environmentally sensitive polymer host materials. The coatings will be derived from inorganic transition metal oxides and are thus expected to be economical in materials and preparation, robust, and not subject to environmental degradation. The objective of Phase I is to demonstrate a new highly active photochromic thin film employing a novel means of sensitization of the metal oxide photocoloration process. The thin films may be prepared by vapor deposition (to be investigated in Phase 1) or by thermal decomposition of appropriate precursors, compatible with float glass plant operations. Successful completion of the project will yield a 6 in. square sample of the new material and preliminary performance and life testing results. This will form a basis of a more extensive Phase II project in which the composition and processing are optimized, and in which the long-term environmental stability of the materials is characterized and improved. 


\section{IGC Advanced Superconductors \\ 1875 Thomaston Avenue \\ Waterbury, CT 06706}

\section{A Novel Method for Manufacture of High Temperature Superconducting Colls for High Temperature Operation}

Leszek R. Motowidlo

203/753-5215

Funding Profile

FY $94-\$ 75,000$

The primary objective of this project is the development of high temperature superconducting (HTS) coil technology suitable to produce at least one Tesla at pumped liquid nitrogen temperatures. The Phase I project will continue to develop a new approach for increasing the performance of HTS coils for high temperature operation. The technical approach being followed in this work will allow achievement of critical current densities $\left(J_{0}\right)$ equivalent to the best results obtainable by short sample pressing. The achievement of $J_{0}$ values on the order of 30,000 to $60,000 \mathrm{~A} / \mathrm{cm}^{2}$ in the final coil configuration would then allow, for the first time, serious consideration of devices to be operated at cryogenic temperatures such as pumped liquid nitrogen (64 K) with magnetic field generation of at least one Tesla. 
JX Crystals, Inc.

4817 174th Place, S.E.

Issaquah, WA 98027

\section{A Clean and Efficlent Thermophotovoltalc Generator for Electric Vehicles}

Lewis M. Fraas

206/392-5237

Date Started: August 15, 1994

Funding Profile

FY $94-\$ 74,932$

A quiet, lightweight, clean electric power source will be built, in which natural gas burns continuously in a ceramic tube, the tube glows red hot, and photovoltaic cells receive the infrared radiation from this emitter and convert it to electric power. In effect, "solar" cells are used with a manmade "sun" created by burning natural gas. Because the natural gas is burned at a continuous high temperature in the photovoltaic unit, it is expected to burn more completely and cleanly than it does in the periodically exploding internal combustion engine. Initial benchtop experiments have already shown that this generator is fifty times cleaner with respect to hydrocarbon and carbon monoxide emissions. Such a generator has only recently become feasible as a result of newly fabricated gallium antimonide cells. These new cells are much more sensitive in the infrared spectrum than traditional solar cells. In Phase I, a small benchtop thermophotovoltaic generator will be built, and sufficient data collected to demonstrate that such a generator can operate cleaily and efficiently at economical power densities. The long term goal of this project is to build a generator with sufficient power to charge onboard vehicle batteries, resulting in an electric vehicle without the present constraint of limited driving range. Further, the design of this generator will emphasize cost-effectiveness in volume production, so that this project could lead to commercially viable products in all present and future markets for electric generators. 


\section{Membrane Technology and Research, Inc. 1380 Willow Road \\ Sulte 103 \\ Menlo Park, CA 94025}

\section{A Membrane Reactor for the Production of Hydrogen Fuel from Hydrocarbon Llquids}

Ingo Pinnau

415/328-2228

Fundina Profile

Date Started: August 15, 1994

FY $94-\$ 75,000$

Research and development efforts are under way to produce the "green car"-an energyefficient, pollution-free, economical vehicle that is also appealing to consumers. A good approach to meeting the goals of the "green car" is to use a fuel that is energy-efficient, pollution-free, economical, and safe. This project will investigate an innovative membrane-based process that would make hydrogen feasible as an automobile fuel. Ultrathin metal composite membranes will be used in an on-board membrane reactor to produce extremely pure hydrogen fuel by dehydrogenation of hydrocarbon liquid. The spent liquid is stored in the automobile and recycled at the filling station, enabling the "green car" to use the existing fuel supply network. The use of a hydrocarbon liquid as the hydrogen source eliminates the problem of fuel safety. In Phase I, catalytically active metal membranes on high-temperature polymer supports will be prepared and characterized. The membranes will be installed in a membrane reactor to determine the hydrogen conversion efficiency and production rate. The size, cost, and weight of a membrane reactor to power a 2,000-1b automobile will be estimated. In Phase II, the membranes will be scaled up for a pilot-scale membrane reactor to demonstrate the continuous production of hydrogen as an automotive fuel. 
Quantum Group, Inc.

1211 Sorrento Valley Road

San Dlego, CA 92121

69. Thermophotovoltaic Generator Efficlency Improvement

Glen A. Holmquist

619/457-3048

Funding Profile

Date Started: August 15, 1994

FY $94-\$ 74,500$

The objective of the Phase I effort is to perform a feasibility/modeling study for a high temperature $\left(1700\right.$ to $\left.2200^{\circ} \mathrm{C}\right)$ combustion powered, high-efficiency thermophotovoltaic electrical generator. The combination of existing materials and technologies will be tested and brought together to achieve the high-efficiency goal. Superemitters that concentrate radiant flux in quantum transitions emission peaks are available for study and measurement. New photovoltaics that match the superemitter peaks with efficient photon conversion are becoming economically feasible. 


\section{Selee Corporation}

700 Shepherd Street

Hendersonville, NC 28792

60. A Novel High Strength Cerla-Zirconia Toughened Alumina Ceramic with Superior High Temperature Corrosion and Erosion Resistance

Giulio A. Rossi

704/697-2411

Funding Profile

Date Started: August 15, 1994

FY $94-\$ 75,000$

This project will develop a novel ceramic material, made of a ceria-zirconia $\left(\mathrm{CeO}_{2}-\mathrm{ZrO}_{2}\right)$ toughened alumina $\left(\mathrm{Al}_{2} \mathrm{O}_{3}\right)$, which is expected to exhibit superior strength and corrosion (alkali, sulphate) and erosion resistance in high temperature environments, such as coalderived hot gases. This material will be fabricated for convenience in the shape of a reticulated foam in order to provide enough surface area to alkali and sulphate exposure and to compare its performance with other foams with different compositions. The open cell structure will be made by impregnating of a polyurethane foam with an aqueous ceramic slurry, followed by drying and firing to burn the organic material and densify the foam struts at high temperatures. Samples of the material will be exposed to alkali- and sulphur-containing species at high temperatures, and the change in physical, chemical, and mechanical properties will be measured, vis-á-vis selected reference materials. 


\section{Space Power, Inc. \\ 621 River Oaks Parkway \\ San Jose, CA 95134}

\section{Design and Applications of Close-Spaced Thermionic Converters with Novel Isothermal Electrodes}

Gary O. Fitzpatrick

408/434-9500

Funding Profile

Date Started: August 15, 1994

FY $94-\$ 74,342$

It will be demonstrated in Phase I, by analysis and experiment, that electrodes for thermionic converters, having heat pipes incorporated in the electrode structure, accommodate high interelectrode heat flux without distortion. These results will enable close-spaced converters with electrode gaps of $5 \mu \mathrm{m}$ or smaller. Such a converter can be $13 \%$ efficient with an emitter temperature of only $1300 \mathrm{~K}$. This is a new approach to enhanced energy conversion efficiency that can significantly increase overall efficiency of power generation at competitive cost. The analysis of the electrodes will consider heat transfer, mechanical deformation, and thermionic performance. Trade-off of heat flux and physical dimensions will lead to an optimum design. Experiments will use laser interferometry to characterize and confirm the capabilities of the isothermal electrode. An application study will quantify the commercial benefits that can reasonably be expected from this improved performance, which can be commercialized in this decade. Follow-on work would include fabrication of an operating module of close-spaced thermionic converters with the isothermal electrodes. 
TDA Research, Inc. 12345 West 52nd Avenue

Wheat Ridge, CO 80033

\section{Rare Earth Endohedral Fullerenes as New Nonlinear Optical Materials}

John Michael Alford

303/940-2301

Funding Profile

Date Started: August 15, 1994

FY $94-\$ 75,000$

Computers using light beams instead of wires are the fastest known type of computer. Many of the main components of optical computers such as the optical switches that are its fundamental building blocks are fabricated from third order nonlinear optical (NLO) materials. Unfortunately, the best currently available third order materials have NLO effects that are two to four orders of magnitude smaller than are needed for commercial devices driven by moderate power diode lasers. Endohedral fullerenes (closed cage carbon molecules with a rare earth atom or atoms trapped inside) are believed to possess large optical nonlinearitites. Significantly, these predicted nonlinear effects are optimally located for use with infrared (IR) laser diodes. Additionally, electronic interactions between the fullerene and metal atom may provide a natural way to obtain optical control of the materials properties and allow for optical switching of the nonlinearity. In spite of the fact that endohedral fullerenes were first produced almost three years ago, insufficient material exists to determine if they actually have the NLO properties predicted by the theorists. This is primarily a result of the difficulty in purifying the materials. Therefore, in Phase I a new type of large scale preconcentration step will be used along with high performance liquid chromatography to purify sufficient quantities of endohedral fullerenes for NLO characterization. The optical properties of the materials will be measured using four wave mixing spectroscopy and other types of nonlinear spectroscopy. 


\title{
Thermal Electric Devices, Inc.
} 1009 Bradbury Drive, S.E.

\section{Albuquerque, NM 87106;}

\section{Development of Metal Hydride Materials for High Coefficlent of Performance Heat Pumps}

\author{
K. Thomas Feldman \\ 505/272-7505
}

Funding Profile

Date Started: August 15, 1994

FY $94-\$ 74,999$

This project will develop improved metal hydride materials for a new hydride heat pump that is environmentally clean and potentially twice as efficient as the best current systems. New thermodynamic processes have been developed for hydride heat pumps that are significantly more efficient and utilize no chlorofluorocarbons (CFCs), that must be phased out of use by 1995 . The best current refrigerators operating with less damaging hydrochlorofluorcarbon (HCFC) refrigerants have a coefficient of performance or COP = 1.5 , while the proposed new hydride heat pump has a theoretical $C O P=3.3$. Current research has demonstrated that hydride heat pumps are feasible and very promising, but improved hydride materials are needed to achieve their full potential. Improved hydride heat exchangers are needed that have more rapid heat transfer and hydrogen flow. Hydrides have low thermal conductivity so that rapid heat transfer into and out of the hydride bed is difficult. Also, hydride particles tend to become smaller and compacted during use and this blocks the free flow of hydrogen into and out of the hydride bed. In Phase I the approach to the improved hydride materials involves coating the metal hydride particles with a thin layer of copper and then compressing the coated particles into porous heat exchangers which can provide more rapid and effective heat transfer and hydrogen flow. When developed, this technology will allow nearly a $50 \%$ reduction in the electric power required by refrigerators/freezers, air conditioners, and heat pumps used in both domestic and commercial applications including vehicles. The new system will be smaller, weigh less, and cost about the same as conventional refrigeration equipment. The system does not require CFCs or HCFCs, so it is inherently clean and has no adverse environmental impact. 


\section{Visual Computing Systems Corporation \\ 9540 Highway 150 \\ Box 250 \\ Greenville, IN 47124}

\section{An Energy Efficlent Electric Vehicle}

Roy Kessinger

812/923-7474

Funding Profile

Date Started: August 15, 1994

FY $94-\$ 74,817$

This project is pursuing the design and production of a line of integrated mechanical, electronic, and software modules to provide a logical framework within which motion control systems of great efficiency and versatility may be designed and constructed. These products are called general-purpose motion modules (GPMs). GPMs are, in effect, mechatronic electric motor systems, integrating the motor, transmission, sensing, and control functions for a single axis of motion into a lightweight modular package. This functional integration will achieve significant reductions in size and weight, while increasing output torque and electromechanical conversion efficiency. Due to the high power-to-weight ratio of these devices, as well as their high operating efficiency, automotive applications are particularly appropriate for GPM technology. Phase I will expand the current GPM baseline designs to allow their use in numerous automotive systems. A high-level design will be produced, at the mechanical, electrical, and control levels, of a vehicle employing a regenerative powertrain based on general-purpose motion modules (GPMs). Current GPM designs will be modified to provide the high torque and high efficiency required by practical electric vehicles. Predictions of overall vehicle efficiency will be produced. Throughout the project, computer-based simulation will be employed to facilitate design and to allow system performance to be predicted. 


\title{
PHASE II SBIR PROJECTS
}

\author{
Adelphi Technology, Inc. \\ 2181 Park Boulevard \\ Palo Alto, CA 94306
}

65. Parametric Radiation as an Intense Monochromatic X-Ray Source*

Melvin A. Piestrup

415/328-7337

Funding Profile

Date Started: March 31, 1992

FY 92 - $\$ 292,000$

Anticipated Duration: 2 Years

FY $93-\$ 208,000$

The objective of the program is to investigate the use of parametric $x$-ray radiation (PXR) as a low-cost, pulsed, tuneable $X$-ray source. PXR generation is achieved by placing natural or synthetic crystals, or multilayer structures, into a relativistic electron beam. The virtual photons associated with the fields of the electrons are Bragg reflected by the periodic crystal lattice, and real $x$-rays appear at the Bragg angle. The production process is thus analogous to $x$-ray diffraction by crystals, except that the $x$-ray beam incident at the Bragg angle is replaced by a relativistic electron beam. This source is quasi-monochromatic, directional, tuneable, and polarizable. Bandwidths can be adjusted from about $0.1 \%$ to $50 \%$. Parametric $x$-ray radiators can be designed to produce specified $x$-ray energies and bandwidths by careful selection of the crystal radiator, the Bragg angle, and electron-beam parameters. In contrast to synchrotron radiation, PXR requires only the moderate electron-beam energies of inexpensive linear accelerators. Phase I research has demonstrated that PXR is a viable source from 5 to $30 \mathrm{keV}$. The $x$-ray spectrum from silicon and mosaic graphite crystal was measured using a $90 \mathrm{MeV}$ electron beam. The intensity from graphite was found to be roughly an order of magnitude higher than that from silicon radiators. Up to six harmonics could easily be observed. During Phase II, the range of the PXR source will be extended down to $1 \mathrm{keV}$ and above $30 \mathrm{keV}$. High-intensity $x$-ray emission using high average electron-beam currents will also be demonstrated. Natural and synthetic crystal and multilayer structures will be used in these experiments. An improved theoretical model for the spectral distribution will be derived and a theory of PXR production by multilayer structures will be developed. Two applications will be studied: medical imaging of the arteries of the heart and the production of $\mathrm{X}$-ray lithographs using soft $\mathrm{X}$-ray emission. "Project Completed 


\section{Advanced Refractory Technologies, Inc. 699 Hertel Avenue \\ Buffalo, NY 14207}

\section{Porous Aluminum Nitride Part Fabrication to Support Advanced Battery Development}

Thomas J. Mroz, Jr.

716/875-4091

Funding Profile

Date Started: April 1, 1994

FY $94-\$ 599,703$

In Phase I, sintered porous Aluminum Nitride (AIN) materials were shown to be suitable for separators in lithium-metal sulfide batteries. The sintered separator improves the structural integrity of the battery and allows reduction of the cell size. However, the current cost of AIN separators is more than the currently used Magnesium Oxide (MgO) powder materials. Methods of decreasing the cost of AIN separators have been identified - they involve reduction in powder cost, improvements in tape processing methods, and utilization of continuous firing methods. This project will investigate methods of obtaining these cost reductions through processing improvements. Additionally, extended battery testing will be performed to assist in separator plate optimization and to develop baseline characteristics for baseline development. Opportunities within the process have been ideritified that will provide suitable cost savings which would result in a cost competitive separator concept. Battery fabricators identified in Phase I will be used to evaluate these AIN separators in preparation for commercialization of the concept in Phase III. Other non-battery opportunities for the porous AIN structure have been identified which provide additional avenues for product commercialization. 


\section{American Superconductor Corporation \\ 2 Technology Drive \\ Westborough, MA 01681}

\section{OxIde Dispersion Strengthened Silver for Use In High-Temperature Superconductor Composite Wires}

Gilbert N. Riley, Jr.

508/836-4200

Funding Profile

Date Started: July 18, 1994

FY $94-\$ 125,000$

FY $95-\$ 475,000$

The strengthening of high-temperature superconductor (HTS) composite conductors with oxygen dispersion strengthened (ODS) silver is planned. State-of-the-art HTS composite conductors consist of ceramic superconductor filaments encased in a silver (Ag) sheath. For reasons of chemical compatibility and oxygen permeability, silver is the only material that can be used to sheathe HTS. However, the current method of manufacture weakens the silver sheath, resulting in reduced HTS conductor strengths. The low strength of these composite conductors is a major obstacle in the development of HTS wires for applications requiring robust conductors such as power transmission cables, SMES, and motors. ODS increases the strength of the sheath, while maintaining chemical compatibility and oxygen permeability of silver. In Phase I, two ODS-Ag systems and a method of fabrication were identified that provide the necessary thermomechanical stability and strength. Specific process issues unique to the materials and methods identified in Phase I will be addressed. Using insights gained from process-propertymicrostructure relationships and statistically designed experimental techniques, novel processes that simultaneously optimize the performance of the ODS-Ag sheath and the HTS will be developed. The resulting technology will be scaled up so that long lengths $(\sim 1 \mathrm{~km})$ of high-strength and high-performance HTS composite conductor can be manufactured on a routine basis. 


\section{Chemat Technology, Inc. \\ 19365 Business Center Drive \\ Sulte 8 \\ Northridge, CA 91324}

\section{Capacitive Energy Storage Using High Surface Area Hafnlum Compounds}

Haixing Zheng

818/727/9786

Funding Profile

Date Started: July 18, 1994

FY $94-\$ 125,000$

FY $95-\$ 475,000$

High surface area materials have diverse applications, such as for energy storage systems and for catalytic converters. In Phase I, the feasibility of fabricating transition metal compounds with high surface area and high double layer capacitance, using the sol-gel process, has been demonstrated, and a supercapacitor cell has been prepared in the Phase I research. Several approaches have been tried to prepare these carbides, nitrides, and borides of high surface area with the focus on hafnium compounds which have the highest capacitance of $>200 \mu \mathrm{F} / \mathrm{cm}^{2}$. Hafnium carbonitrides with surface area up to $123 \mathrm{~m}^{2} / \mathrm{g}$ have been fabricated and the supercapacitor cell has been constructed using these porous hafnium carbonitrides. The cell has an energy density of $6.4 \mathrm{~J} / \mathrm{g}$, which is close to the $10 \mathrm{~J} / \mathrm{g}$ energy density of ruthenium dioxide $\left(\mathrm{RuO}_{2}\right)$. In Phase II, energy storage capabilities will be enhanced by increasing the surface area of hafnium carbonitride and tailoring the chemistry of the pore surface. The best processing variables for fabricating the capacitive energy storage cells will be identified. The optimized cells will be tested for various properties: operation temperature, working voltage, capacitance, equivalence series resistance, and leakage current. All technical parameters will be measured and a technical database on these supercapacitors will be prepared for future commercialization of the supercapacitors. The process will be scaled up to pilot plant stage, and the production cost will be estimated. 
Deacon Research

2440 Embarcadero Way

Palo Alto, CA 94303

69. Solld State UV Light Source*

David Deacon

415/493-6100

Date Started: July 6, 1992

Funding Profile

Anticipated Duration: 2 Years

FY $92-\$ 333.000$

FY $93-\$ 167,000$

Deacon Research is developing inexpensive, diode laser based sources of coherent radiation in the blue and ultraviolet regions of the spectrum. In the first phase of this program, we have achieved high efficiency doubling of a diode laser, and anchored these results to the theoretical structure needed to scale to other configurations. We intend to develop a system that produces high conversion efficiency into the ultraviolet. If we succeed, we will have created a revolutionary new tool for use by the biological analytical and scientific communities. The combined advantages of long laser lifetime and rugged components will enable this product to rapidly penetrate existing UV laser markets, and will open up new applications due to its small volume and low power consumption.

"Project Completed 
ISM Technologles, Inc.

9986 Carroll Canyon Road

San Dlogo, CA 92131

70. Low Temperature Deposition of Titanlum Nitride

Anthony J. Perry

619/530-2332

Funding Profile

Date Started: July 18, 1994

FY $94-\$ 124,933$

FY $95-\$ 474,744$

Titanium Nitride (TiN) has been found to be an excellent coating for wear resistant applications. However, the deposition temperature of about $450^{\circ} \mathrm{C}$ is far too high for many applications for machine component parts made from alloy steels or aluminum alloys, where deposition temperatures over $150^{\circ} \mathrm{C}$ would deleteriously affect the mechanical properties of the substrates. When TiN coatings deposited at such a temperature, using current conventional industrial technologies, the micro-structure is not dense and the resulting coatings have mechanical properties far inferior to those made at the higher temperatures. Phase I demonstrated that hard, well-adhering TiN with low residual stress and a dense micro-structure can indeed be made at $150^{\circ} \mathrm{C}$ (by reactive deposition from a cathodic arc evaporation source) using the Hyper-lon process developed by ISM Technologies. In the Hyper-Ion process, a pulsed high voltage bias is applied to the work-piece which produces this marked improvement in properties. In Phase II, the deposition process should be further developed and refined to produce a well-defined coating process, which can be scaled up into production, aimed at providing optimised wear resistance industrial parts. 


\section{Ultramet}

12173 Montague Street

Pacolma CA 01331

\section{Coated Mlcrograln Carbldes for Wear Reslstance}

Andrew J. Sherman

818/899-0236

Funding Profile

Date Started: July 18, 1994

FY $94-\$ 124,908$

FY $95-\$ 474,649$

Micrograin carbides are small grain size (1-5 $\mu \mathrm{m}$ diameter) particles of tungsten carbide (WC) that have been "cemented" together with a predominantly cobalt matrix by liquidphase sintering. The result is an excellent material for carbide cutting tools and other wear- and/or corrosion-resistant parts, because their finer grain size yields better mechanical properties than typical carbide tools (with grain sizes 20-50 $\mu \mathrm{m}$ ). Some of their potential advantage is negated, however, by the difficulty of handling such fine powders and mixing them with cobalt powders to form the blend which is then preformed and sintered. Problems arising during handling and blending include increased impurity content, nonhomogeneous distribution of matrix powders, and WC-WC particle contact, all of which lower mechanical properties in the finished part. Also, substantial grain growth occurs during the liquid-phase sintering step. The result is that cobalt content must be increased to achieve the desired fracture toughness and transverse rupture strength, with a corresponding decrease in tool hardness and life and an increase in tool cost. In Phase I, the feasibility of coating individual WC grains with the proper thickness of cobalt matrix was demonstrated. After consolidation, the problems of WC-WC particle contact and mixed carbide formation were found to be eliminated. Improved mechanical properties and performance over conventional micrograin carbides were obtained. The process permitted faster consolidation times and yielded lower impurity content with less deleterious interaction between matrix and carbide, as well as a large reduction in the amount of cobalt required. In Phase II, the process for coating WC/mixed carbide powders with cobalt will be optimized. A $40 \%$ increase in tool life (reduced wear rate) at constant mechanical properties and lower cobalt content, and/or a $50 \%$ increase in tool toughness (and hence strength) at constant wear is expected. 
X-Ray Optical Systoms, Inc.

1400 Washington Avenue

Albany, NY 12222

72. Kumakhov Lons with Rotating Anode to Obtain an X-Ray Source Which is an Advantageous Alternative to Synchrotron*

Alexandre I. Kolomitsev

$518 / 442-5250$

Funding Profile

Date Started: July 6, 1992

FY $92-\$ 331,000$

Anticipated Duration: 2 Years

FY $93-\$ 165,000$

Material analysis studies that require well-collimated $x$-ray beams typically have long measurement times or require use of a synchrotron. The ability to substantially shorten data collection time for measurements such as diffraction would make these techniques more widely available and improve our national capacity to perform new materials research. Use of capillary based $x$-ray optics to collect and collimate a divergent beam laboratory $x$-ray source appears to be feasible, based on experimental and modeling data. The proposed project will include design, fabrication, and characterization of $x$-ray optics. These optics would be used in diffraction experiments to investigate the benefits from inclusion of the optic in the experimental setup. X-Ray Optical Systems, Inc. and its consultants from the Institute for Roentgen Optical Systems, Moscow, and the Center for $X$-Ray Optics, Albany, the groups most qualified with optics, will work with diffraction experts to evaluate the opportunity.

"Project Completed 


\section{SAMPLE STATEMENT OF WORK}

\section{1) Prolect Oplective}

The proposer shall investigate the electrocatalytic oxidative dehydrogenation of ethylbenzene and butane in solid electrolyte fuel cells. The effort is directed toward defining optimal operating conditions for achieving high yields of styrene and butadiene with simultaneous electric energy generation.

2) The work to be performed consists of the following tasks:

2.1. Construction of tubular stabilized zirconia fuel cells with a platinum cathode and an iron oxide or platinum anode. Both anode materials are quite promising and a decision between the two will be made after prellminary runs.

2.2. Measurement of the styrene cell activity and yleld as a function of temperature, inlet ethylbenzene concentration and external resistive load.

2.3. Measurement of the cell electric power output and overpotential as a function of the operating parameters described in $\mathbf{2 . 2}$.

2.4. Determination of the nature of the overpotential according to the results of 2.3. If ohmic overpotential dominates, a small well mixed cell with thin (150 microns) electrolyte discs will be constructed to increase power density.

2.5. Development of correlation for styrene yield and electrical power output in terms of operating and design parameters for use in future scale up.

2.6. Repeat tasks 2.2. through 2.5. using butane and/or butene as the fuel.

2.7. Prellminary engineering and economic analysis according to the results of 2.2. through 2.6.

3) Deliverables

The proposer shall provide the data of experiments performed according to paragraphs 2.2., 2.3., 2.4., 2.5. and 2.6. along with analyses and conclusions based on this data.

4) Performance Schedule

4.1. Complete construction of cells 3 months after start of work.

4.2. Complete ethylbenzene experiments within 12 months after start of work.

4.3. Complete butane and butene experiments and data analysis 20 months after start of work.

4.4. Complete data correlation, economic analysis and final report 24 months after start of work. 


\section{PROGRAM DATA}

\section{OFFICE OF BASIC ENEROY SCIENCES}

\section{DIVISION OF ADVANCED ENEROY PROJECTS}

\section{BUDCET}

FY 1993

$\$ 10,900,000$

300,000

FY 1984

FY 1985

(REQUEST)

$\$ 11,400,000$

300,000
$\$ 11,086,000$

300,000
OPERATING
EQUIPMENT

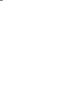

On February 12 Supplemental Appropriations Act for 1994." A provision in the law is a $3 \%$ rescission in portions of certain government programs. FY 1994 budgets for all projects in the grant and laboratory programs were reduced to comply with that provision. However, the FY 1994 funding shown for each project is the pre-rescission value.

\section{DISTRIBUTION OF FY 1994 FUNDS}

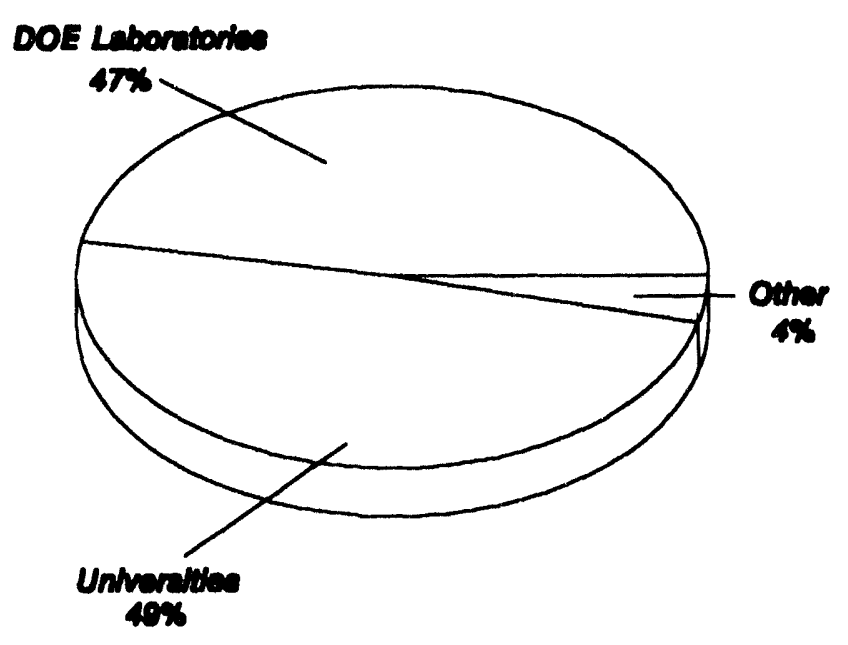


INVESTIGATOR INDEX

(Project Numbers)

Alford, John Michael

Anders, Simone

Bardsley, J. N.

Benson, David K.

Besmann, Theodore $M$.

Bionta, Richard M.

Bromberg, Leslie

Brown, Ian $\mathbf{G}$.

Chaiko, David S.

Crivello, James V.

Deacon, David

Farmer, Joseph C.

Feldman, K. Thomas

Fitzpatrick, Gary 0.

Fraas, Lewis $M$.

Friedman, Lewis

Gidley, David W.

Gorlov, Alexander M.

Greene, Philip

Gruen, Dieter M.

Gschneidner, Jr., Karl A.

Hanna, Mark C.

Harris, Michael $T$.

Ho, Kai-Ming

Holmquist, Glen A.

Horwitz, E. Philip

Huffman, Donald R.

Hunt, Thomas K.

Joshi, Chan J.

Kapteyn, Henry C.

Kazmerski, Lawrence $L$.

Kessinger, Roy

Kolomitsev, Alexandre I.

Lagow, Richard J.

Leung, K.a-Ngo

Matthews, Ronald D.
62

21

25

36

40

26

32

22

4

45

69

27

63

61

57

10

33

39

46

5

2

37

41

3

59

6

9

54

12

52

38

64

72

49

23

50
Mattick, Arthur T.

51

Michl, Josef 15

Motowidlo, Leszek R. $\quad 56$

Mroz, Jr., Thomas J. $\quad 66$

Nastasi, Michael 29

Nebel, Richard A. $\quad 30$

Pantell, Richard H. $\quad 47$

Pekala, Richard W. 28

Perry, Anthony J. $\quad 70$

Piestrup, Melvin A. $\quad 65$

Pinnau, Ingo 58

Prelas, Mark A. $\quad 35$

Putterman, Seth J. 13

Rabitz, Herschel 43

Rauh, R. David 55

Rhodes, Charles K. 19

Riley, Jr., Gilbert N. $\quad 67$

Rocca, Jorge J. 16

Rosen, Moshe 20

Rossi, Giulio A. $\quad 60$

Rubin, Michael D. 24

Schuessler, Hans A. $\quad 48$

Seal, Michael R. $\quad 53$

Sherman, Andrew J. $\quad 71$

Skelly, David W. $\quad 17$

Smith, Paul 14

Stangle, Gregory C. 1

Tomczuk, Zygmunt 7

Tomkiewicz, Micha 11

Tsao, George T. 44

Warren, Roger W. 31

Was, Gary S. $\quad 34$

Wasielewski, Michael R. 8

Weinstein, Roy 18

Woodward, Jonathan $\quad 42$

Zheng, Haixing 68 


\section{INSTITUTIONAL INDEX}

\section{(Project Numbers)}

Adelphi Technology, Inc.

Advanced Modular Power Systems, Inc.

Advanced Refractory Technologies, Inc.

Alfred University

American Superconductor Corporation

Ames Laboratory

Argonne National Laboratory

Arizona, University of

Brookhaven National Laboratory

Brooklyn College of City University of New York

California, University of, Los Angeles

California, University of, Santa Barbara

Chemat Technology, Inc.

Colorado, University of

Colorado State University

Deacon Research

EIC Laboratories, Inc.

General Electric Company

Houston, University of

IGC Advanced Superconductors

Illinois, University of, Chicago

ISM Technologies, Inc.

Johns Hopkins University

JX Crystals, Inc.

Lawrence Berkeley Laboratory

Lawrence Livermore National Laboratory

Los Alamos National Laboratory

Massachusetts Institute of Technology

Membrane Technology and Research, Inc.

Michigan, University of

Missouri, University of

National Renewable Energy Laboratory

Northeastern University

Oak Ridge National Laboratory

Princeton University
65
54
66
1
67
2,3

65
54
66
1
67
2,3

$4,5,6,7,8$

9

10

11

12,13

14

68

15

16

69

55

17

18

56

19

70

20

57

$21,22,23,24$

$25,26,27,28$

$29,30,31$

32

58

33,34

35

$36,37,38$

39

$40,41,42$

43 


\section{INSTITUTIONAL INDEX, Cont.d}

\section{(Project Numbers)}

Purdue University

Quantum Group, Inc.

Rensselaer Polytechnic Institute

Science Research Laboratory

Selee Corporation

Space Power, Inc.

Stanford University

TDA Research, Inc.

Texas A\&M University

Texas, University of, Austin 49,50

Thermal Electric Devices, Inc.

Ultramet

Visual Computing Systems Corporation

Washington, University of

Washington State University

Western Washington University

53

$X$-Ray Optical Systems, Inc.

72 
FACSIMILE COVER SHEET

DATE:

TO: Division of Advanced Energy Projects, ER-16 U.S. Department of Energy Washington, D.C. 20585

FROM:

(inc. tel \#)

SIGNATURE:

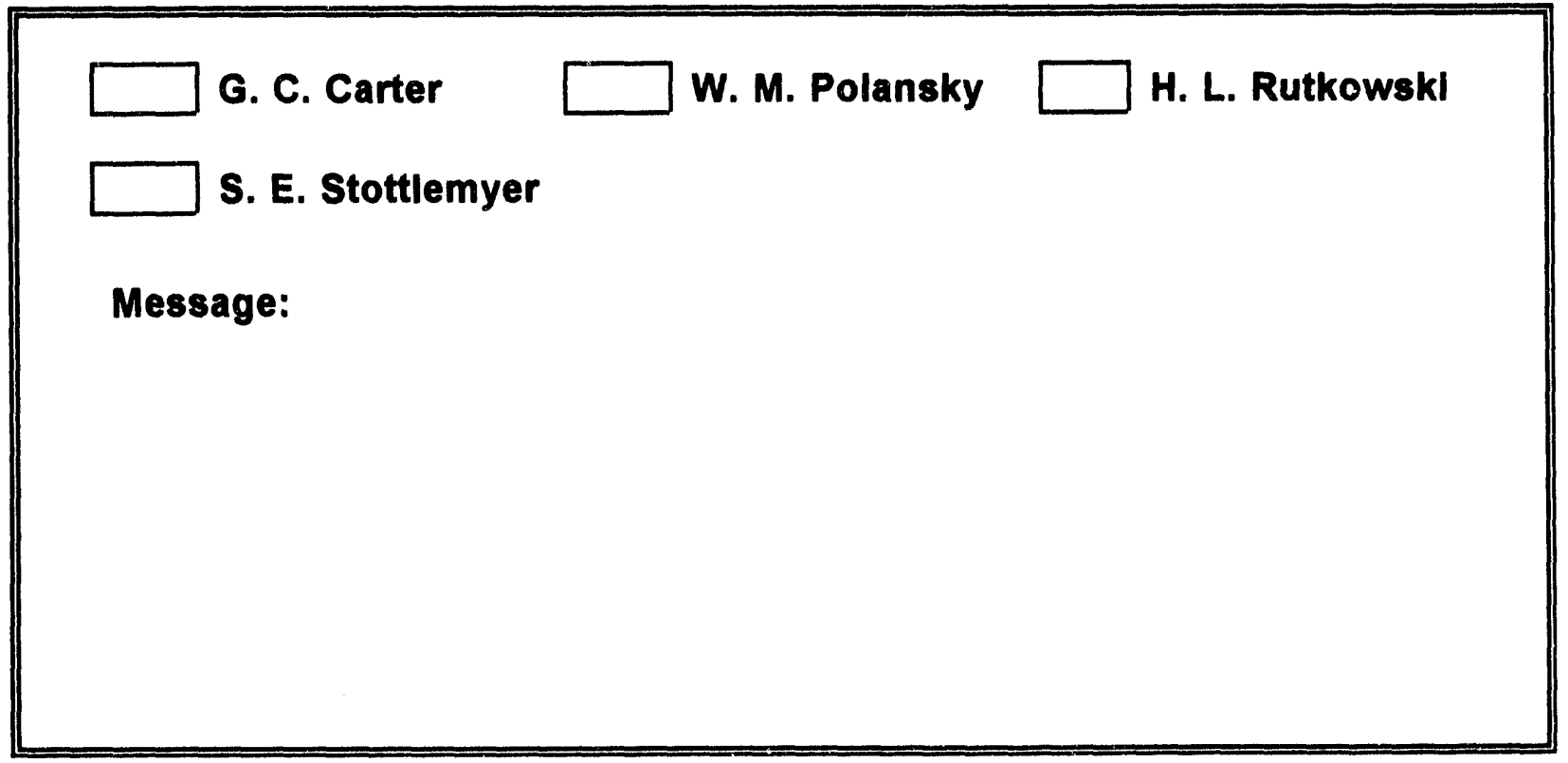

This document consists of pages (including this cover).

TRANSMIT: $301 / 903-6067$

VERIFY: $301 / 903-5995$ 

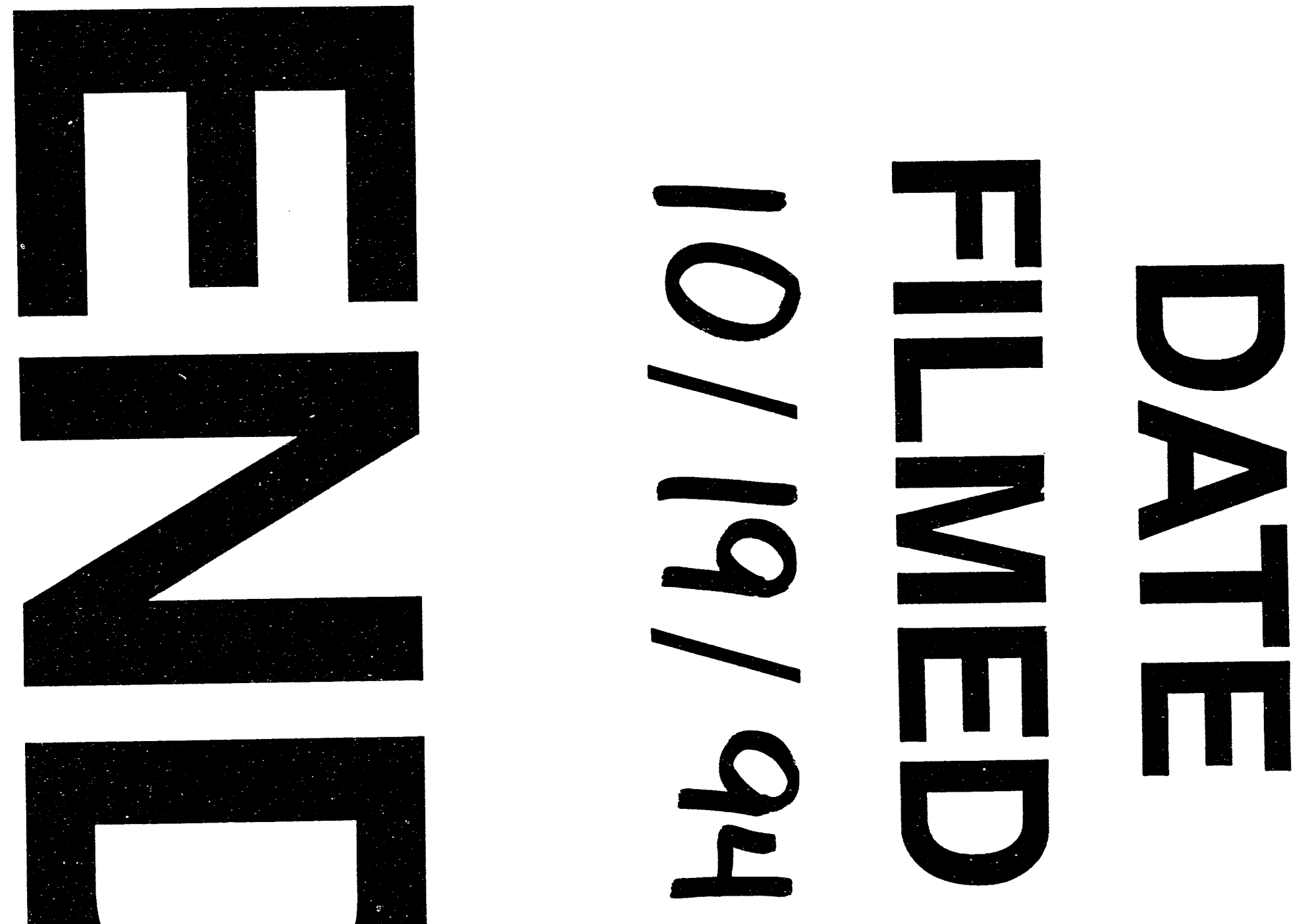


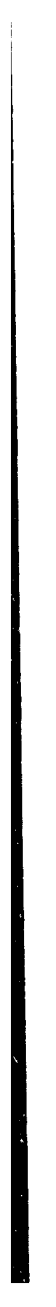

